\title{
Design and experimental implementation of a wind energy conversion platform with education and research capabilities
}

\author{
Elhoussin Elbouchikhi ${ }^{\mathrm{a}, *}$, Gilles Feld ${ }^{\mathrm{a}}$, Yassine Amirat ${ }^{\mathrm{a}}$, Mohamed Benbouzid ${ }^{\mathrm{b}, \mathrm{c}}$, \\ Franck Le Gall ${ }^{\text {a }}$
}

a ISEN Yncréa Ouest, UMR CNRS 6027 IRDL, Rue Cuirassé Bretagne, 29200, Brest, France

${ }^{\mathrm{b}}$ University of Brest, UMR CNRS 6027 IRDL, 29238 Brest, France

' Shanghai Maritime University, 201306 Shanghai, China

Today, pitch-controlled variable speed wind turbines (WTs) are the most installed Wind Energy Conversion (WEC) systems. They mainly use two types of generators: the permanent magnet synchronous generator (PMSG) and the double-fed induction generator (DFIG). In this paper, the overall configuration of DFIG-based WEC systems is reviewed and its control strategy is experimentally implemented using dSPACE DS1104 controller board. In this context, emphasis is placed on active power transfer management, reactive power compensation, and sinusoidal current injection into the main grid to improve power quality. The built lab-scale prototype allows validating different subsystems operation and demonstrating DFIG-based WEC capabilities.

This paper specifically provides a thorough and consistent step-by-step modeling and control design methodology for a DFIG-based WEC simulation and experimentation platform that could be used for education and research addressing the wind energy conversion timely topic.

\section{Introduction}

Human beings have been using wind energy for thousands of years, but the conversion to electrical energy is more recent. Wind energy harvesting has experienced an explosive growth in the last three decades because of energy crisis, conventional energy production environmental issues, and governments policy encouraging the large penetration of renewable energy resources. Moreover, wind farms are reaching capacity of traditional power plants, which implies same regulation for grid connection in order to meet wind farm grid code requirements [1]. These requirements stipulate that wind farms should contribute to power system control [2]. In particular, wind farms are now increasingly being asked to provide ancillary services such as [3]:

- Enhance energy quality [4]: limit energy fluctuations due to the stochastic nature of the primary energy source, the wind, and curtail if not eliminate harmonics (total harmonic distortion management),

\footnotetext{
* Corresponding author.

E-mail addresses: elhoussin.elbouchikhi@isen-ouest.yncrea.fr (E. Elbouchikhi), gilles.feld@isen-ouest.yncrea.fr (G. Feld), yassine.amirat@isenouest.yncrea.fr (Y. Amirat), Mohamed.Benbouzid@univ-brest.fr (M. Benbouzid), franck.le-gall@isen-ouest.yncrea.fr (F.L. Gall).
} 
- Extended power system voltage and frequency variation limits,

- Voltage/reactive power control and frequency/active power control capabilities [5],

- Low voltage ride-through (LVRT) [6]: modern large-scale WTs are normally required to include systems allowing them to remain connected during short periods of power grid voltage dip or at least reconnect as fast as possible.

Several wind energy system configurations exist depending on the used generator and power converters configurations. Fixed-speed configuration is based on induction generators and the variable-speed one on synchronous or doubly-fed induction generators. Fixed-speed configuration presents the advantages of being simple, robust, reliable, and having low operating and maintenance cost [7]. Nonetheless, this technology suffers from relatively low energy conversion efficiency, high mechanical stress, and a harvested power high fluctuations. Modern WEC technology uses variable-speed configuration, which allow high energy conversion efficiency, improved power quality, and reduced mechanical stress even though it implies additional cost and losses due to the use of power converters. These advantages are possible thanks to advancements in power electronics and the use of advanced control systems [8]. Concerning power converters architecture, WEC with 2-level power converters are the most popular. Other WEC architectures use 3-level power converters [9], solid-state transformer (SST) [10], and boost converters for small wind turbines [11].

DFIG-based WEC systems are the most widely installed wind power generation systems with power rating from hundred $k W$ to several $M W$ [12]. These WEC systems are equipped with full power electronics interfaces and enable reduced-capacity power converters. For this architecture, a back-to-back 2-level voltage source converter (2L - VSC) is used to handle $30 \%$ of the power, with only $30 \%$ of converter losses and allows $\pm 30 \%$ speed variation around synchronous speed. Moreover, active/reactive power control is possible in some degree [13], which allows meeting wind farm grid code requirements [14]. In fact, reactive power capacity directly depends on the rating of the power electronics sizing [8]. This WEC topology allows to implement maximum power point tracking (MPPT) algorithm during partial loading. At DFIG-based WT full loading, the use of pitch control enables effectively limiting the output power. Several MPPT strategies have been proposed and implemented in the literature such as [15]:

- MPPT by optimal tip-speed ratio: Generator speed is adjusted to keep tip-speed ratio constant at its optimum value $\lambda_{\text {opt }}$ for all wind speeds. For this MPPT strategy, both wind speed and generator speed must be measured.

- MPPT by turbine profile: MPPT profile, which is provided by WT manufacturer, delivers corresponding active power reference. Measurement of wind speed is required.

- MPPT by optimal torque control: Torque reference is computed based on the knowledge of the turbine characteristics, particularly maximum power coefficient $C_{p_{\max }}$ and optimal tip-speed ratio $\lambda_{\text {opt }}$. To perform torque control, generator speed must be measured.

- MPPT by Perturb \& Observ: This strategy does not require wind speed or generator speed measurement. The electric output power is measured and generator speed empirically adjusted in order to reach the maximum output power. This approach is generally applied for small-scale wind turbines.

DFIG-based WEC have been widely investigated in the last three decades in order to enhance their performance and ensure seamless operation. Indeed, in [16] authors have proposed a novel control methodology for stability analysis and reactive power compensation in a microgrid with DFIG-based WEC. Moreover, a new control approaches have been proposed in [17], which allow improving the LVRT capability under grid faults. Researchers in academia and industry have proposed several fault-tolerant configurations of DFIG-based WEC for the safe operation during all kinds of grid faults [14]. Furthermore, several studies have been interested in mitigating output power fluctuations, weak fault ride-through capability, and high sensitivity to grid disturbances of DFIG-based WEC [18]. More recent works have dealt with power quality enhancement and power smoothing at the point of grid connection by using energy storage systems (ESSs) [19]. Furthermore, ESSs allow renewable time-shift and capacity firming $[20,21]$. Based on the previously discussed aspects, contributions of this paper are threefold:

- Design and implementation of a dSPACE-based experimental platform for WEC systems digital control.

- A lab-scale prototype is built in order to validate the proposal.

- Advantages offered by the integration of computer technology in DFIG-based WEC control are highlighted through experimental results.

This paper presents a DFIG-based WT topology, modeling, and control. It particularly provides a step-by-step modeling and control design methodology for a simulation and experimental platform that could be used for education and research purposes. Specifically, it highlights advantages and possibilities offered by DFIG-based WEC in terms of inherent active power transfer, voltage conversion functions, and reactive power compensation capability [10]. The former capability is characterized by fast dynamic response (the time constant of the reactive power (voltage control) can be as low as a few milliseconds) and can be used to perform voltage control. Furthermore, frequency control can be achieved by setting non-optimal rotor speed for DFIG, by operating WT as inertial flywheels, or by pitch-control for maximum active power generation. Even tough, the focus is made on DFIG-based WEC active and reactive powers control capabilities, the conclusions drawn from this case study can also be applied to WEC systems driven by PMSG since the power electronics and the control objectives are exactly the same for the two configurations [1]. In order to validate the proposed strategy, experimental results are shown for a low power doubly-fed induction generator. Some relevant experimental results are presented and discussed. These results show 


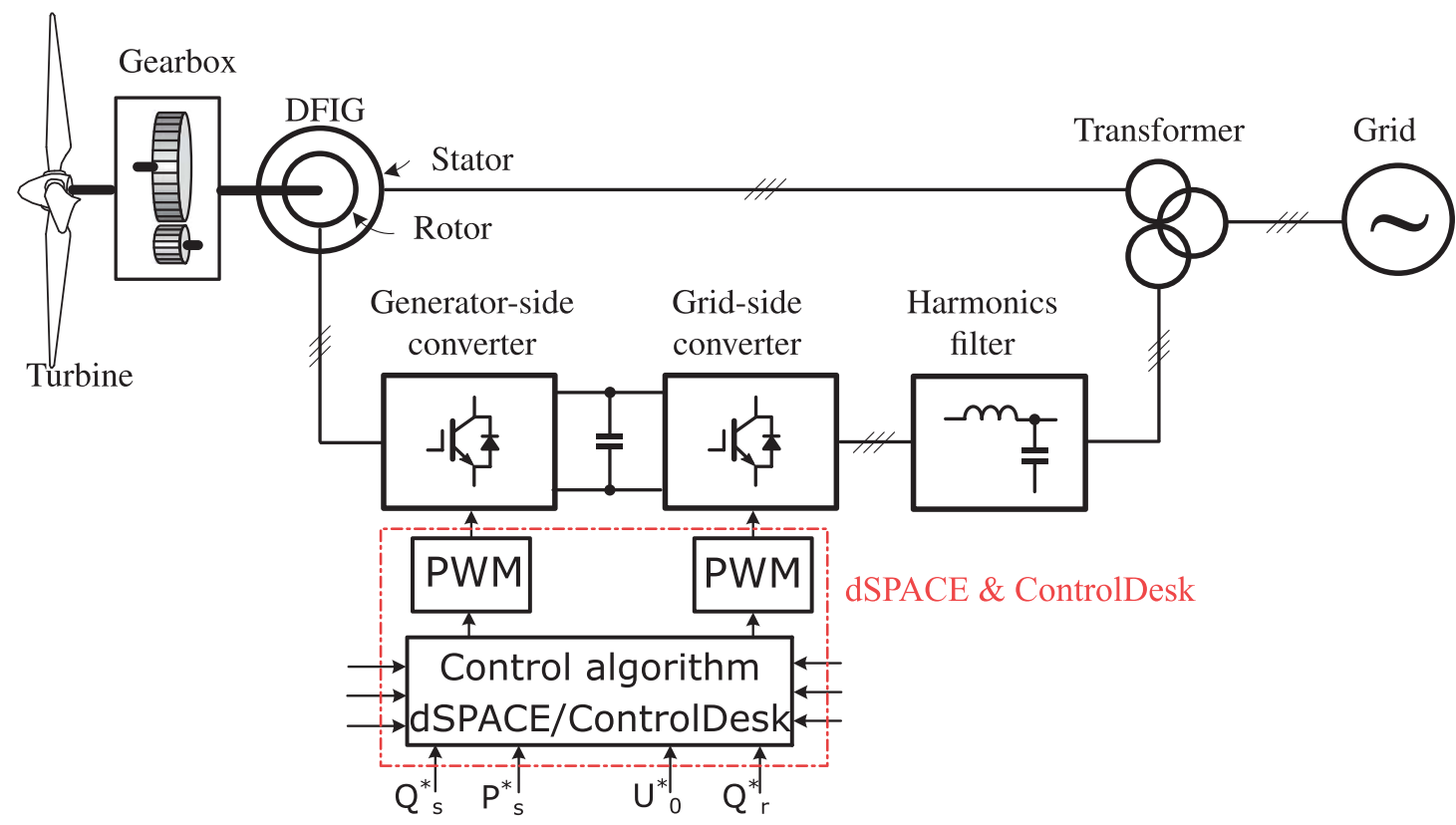

Fig. 1. DFIG-based WEC system configuration [1].

that DFIG-based WEC with voltage control and frequency regulation capabilities can significantly sustain the voltage during grid faults and thus may efficiently support the power grid stability, enhance dynamic behavior, and provide high-quality power.

The rest of the paper is organized as follows. Section 2 deals with the modeling framework of the considered WEC. This model is used for components sizing, control laws design and active and reactive powers management. Section 4 presents some experimental results on actual experimental test-rig equipped with $1.5 \mathrm{~kW}$ DFIG. Section 5 proposes a discussion about the overall assessment of the emulated DFIG-based WEC. Conclusion and future works are summarized in Section 6.

\section{Modeling framework}

DFIG-based WEC system configuration is given by Fig. 1. This figure allows distinguishing WEC subsystems, which are: turbine, DFIG, back-to-back converter (generator-side and grid-side converters), LC filter, and transformer for grid interface.

\subsection{Turbine}

As for airplanes, the aerodynamic shape of the blade changes speed of wind on top and bottom of the blades. The difference in speed produces difference in pressure, hence a lifting force is generated, which creates a torque on the horizontal axe of the turbine. Consequently, a mechanical power is captured by the blades and transmitted to the drivetrain, which is given by

$$
P_{T}=\frac{1}{2} \rho A C_{p}(\lambda, \beta) v_{w}^{3}
$$

- $\rho$ air density in $\mathrm{kg} / \mathrm{m}^{3}$ (at sea level and $20^{\circ} \mathrm{C}: \rho \approx 1.225 \mathrm{~kg} / \mathrm{m}^{3}$ ),

- $A=\pi R_{T}^{2}$ swept area by the blades (wind turbine rotor normally disposed to the wind speed) in $m^{2}$, with $R_{T}$ turbine radius,

- $C_{p}(\lambda, \beta)$ power coefficient of the blade, which depends on tip-speed ratio $\lambda=\frac{R_{T} \Omega_{T}}{v_{w}}$ and pitch angle $\beta$, which is generally used as aerodynamic brake,

- $v_{w}$ wind speed in $m / s e c$,

- $\Omega_{T}$ wind turbine speed in $\mathrm{rad} / \mathrm{sec}$.

Fig. 2(a) shows the operating regions of DFIG-based wind turbine system. We can distinguish mainly three operating regions:

- Parking mode for which brake is on (wind speed is too low to produce energy or too high and dangerous for the blades),

- Generator control where the speed is controlled to capture maximum power (MPPT),

- Stall/pitch control for which blades are used to limit the extracted power from the wind (excess power could harm the turbine and power converters). 


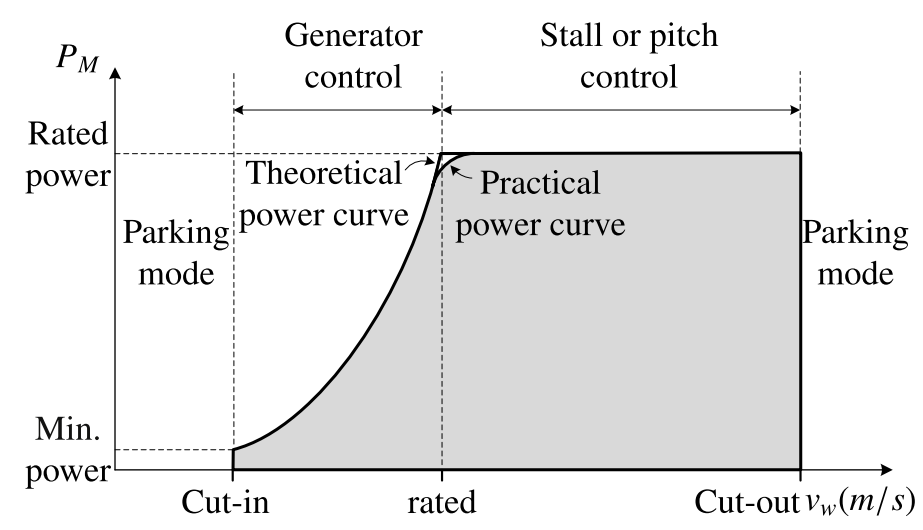

(a) Wind power.

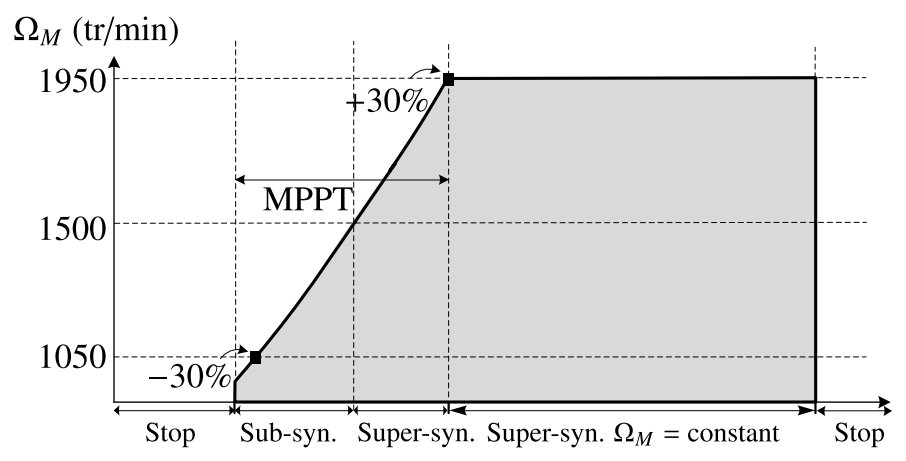

(b) Rotational speed.

Fig. 2. Operating regions in variable-speed WEC.

In generator control zone two operating modes are possible as it can be seen from Fig. 2(b):

- Sub-synchronous operation mode: $\Omega_{M}<\Omega_{s}$, with $\Omega_{s}$ corresponds to synchronous speed $\left(\Omega_{M_{\min }}=70 \% \Omega_{s}\right)$.

- Super-synchronous operation mode: $\Omega_{M}>\Omega_{s}\left(\Omega_{M_{\max }}=130 \% \Omega_{s}\right)$.

\subsection{Gearbox}

A gearbox is typically used in wind turbine to increase rotational speed from the blades low rotating speed to the generator higher speed. The rotational speed of the turbine (low speed shaft) and the rotational speed of the DFIG (high speed shaft) are linked by the following expression:

$$
\Omega_{M}=G_{r} \Omega_{T}
$$

where, $G_{r}$ denotes the gearbox ratio. Therefore, the tip-speed ratio can be expressed as follows:

$$
\lambda=\frac{\Omega_{M} R_{T}}{G_{r} v_{w}}
$$

In order to determine parameters $G_{r}$ and $R_{T}$ characterizing the turbine and gearbox, respectively, let us consider the worst case for rated wind speed $v_{w_{\text {rated }}}$, the DFIG rotational speed is equal to $\Omega_{M_{\max }}=204 \mathrm{rad} / \mathrm{s}$ and its power is the rated power $P_{\mathrm{M}_{\text {rated }}}$. The maximal mechanical losses $P_{l_{\max }}$ due to viscous and dry frictions are given by

$$
P_{l_{\max }}=\Gamma_{v} \Omega_{M_{\max }}+\Gamma_{d} \Omega_{M_{\max }}=f_{v} \Omega_{M_{\max }}^{2}+\Gamma_{d} \Omega_{M_{\max }}
$$

where, $\Gamma_{v}$ and $\Gamma_{d}$ are the viscous and dry torques, respectively. $f_{v}$ corresponds to viscous friction coefficient. Consequently, the power provided by turbine $P_{T}$ is given by

$$
P_{T}=P_{M}+P_{l_{\max }}
$$

Finally, the turbine radius $R_{T}$ can be calculated as follows:

$$
R_{T}=\sqrt{\frac{2 P_{T}}{\pi \rho C_{p_{\max }} v_{w_{\text {rated }}}^{3}}}=\sqrt{\frac{2\left(P_{M}+P_{I_{\max }}\right)}{\pi \rho C_{p_{\max }} v_{w_{\text {rated }}}^{3}}}
$$


where, $C_{p_{\max }}$ corresponds to the maximum value of the power coefficient.

Based on the tip speed ratio equation in (3), the gearbox ratio can be finally deduced:

$$
G_{r}=\frac{R_{T} \Omega_{M_{\max }}}{\lambda_{\text {opt }} v_{w_{\text {rated }}}}
$$

where, $\lambda_{\text {opt }}$ corresponds to the optimal value of the tip-speed ratio.

\subsection{Turbine and gearbox emulation}

Wind generation system study is carried out in a small-scale wind turbine. The base wind speed for the wind turbine is $13 \mathrm{~m} / \mathrm{s}$, the cut-in speed of wind turbine is $5 \mathrm{~m} / \mathrm{s}$ and the cut-out speed of wind turbine is $25 \mathrm{~m} / \mathrm{s}$, and the base rotational speed at the base wind speed is $204 \mathrm{rad} / \mathrm{s}$. Fig. 3 gives the $C_{p}$ curve, the extractable power $P_{T}$, and output torque $\Gamma_{T}$ with respect to rotational speed $\Omega_{M}$ and wind speed $v_{w}$. For the sake of simplicity, the pitch angle $\beta$ is set to zero and no pitch control is implemented in this study.

\section{DFIG-based WEC system modeling and control}

\subsection{Grid-side converter}

\subsubsection{Topology and control}

The grid-side converter topology is given by Fig. 4. This converter is a 2-level voltage source converter, which consists of three-inverter legs, DC bus capacitor $C$, and smoothing inductances. All connected to three-phase main grid. The Insulated Gate Bipolar Transistor (IGBT) switches are controlled using Pulse Width Modulation (PWM), issued from a control algorithm in order to control DC bus voltage and reactive power flow from the rotor (power factor control to participate to system services). Since line currents reference direction is from the grid to converter, active power is positive when power is from the grid to the converter and is negative otherwise.

In the $d q$ reference frame, the inverter voltages are given by

$$
\left[\begin{array}{l}
V_{\text {invd }} \\
V_{\text {invq }}
\end{array}\right]=-R\left[\begin{array}{l}
i_{f d} \\
i_{f q}
\end{array}\right]-L \frac{d}{d t}\left[\begin{array}{c}
i_{f d} \\
i_{f q}
\end{array}\right]+\omega_{s} L\left[\begin{array}{c}
i_{f q} \\
-i_{f d}
\end{array}\right]+\left[\begin{array}{c}
V_{g d} \\
V_{g q}
\end{array}\right]
$$

Where, $\omega_{s}$ corresponds to the grid angular frequency. The $d q$ reference frame is chosen in such way that quadrature $q$-axis is oriented along the grid voltage rotating vector as depicted by Fig. 5. This figure shows that the direct voltage $V_{g d}$ is zero. This choice leads to the following simplifications:

$$
\left\{\begin{array}{l}
V_{i n v d}=-R i_{f d}-L \frac{d}{d t} i_{f d}+\omega_{s} L i_{f q} \\
V_{i n v q}=-R i_{f q}-L \frac{d}{d t} i_{f q}-\omega_{s} L i_{f d}+V_{g q}
\end{array}\right.
$$

These expressions show that there is a coupling terms that must be compensated. Let us consider

$$
\left\{\begin{array}{l}
V_{i n v d_{\text {reg }}}=V_{i n v d}^{*}-\omega_{s} L i_{f q} \\
V_{i n v q_{\text {reg }}}=V_{i n v q}^{*}+\omega_{s} L i_{f d}-V_{g q}
\end{array}\right.
$$

This leads to the following decoupled equations

$$
\left\{\begin{array}{l}
V_{\text {invd }}=-R i_{f d}-L \frac{d}{d t} i_{f d} \\
V_{\text {invq }}=-R i_{f q}-L \frac{d}{d t} i_{f q}
\end{array}\right.
$$

Consequently, the open-loop transfer function can be expressed as:

$$
H_{i}(\mathfrak{s})=-\frac{\frac{1}{R}}{1+\frac{L}{R} \mathfrak{s}} \times K_{p}\left(1+\frac{1}{\tau_{i} \mathfrak{s}}\right)
$$

where, parameter $\mathfrak{s}$ denotes the Laplace variable. PI-controllers parameters for currents loops are computed as follows for the two axes:

$$
\left\{\begin{array}{l}
\tau_{i}=\frac{L}{R} \\
K_{p}=\frac{3 L}{T_{r_{i}}}
\end{array}\right.
$$

where, $T_{r_{i}}$ corresponds to required currents time-response (time to achieve $95 \%$ of final value).

Finally, depending on the operating mode of the turbine, the energy flowing through the DFIG rotor can be from the grid to rotor during sub-synchronous operating mode or the opposite for super-synchronous operating mode. Energy flow is 


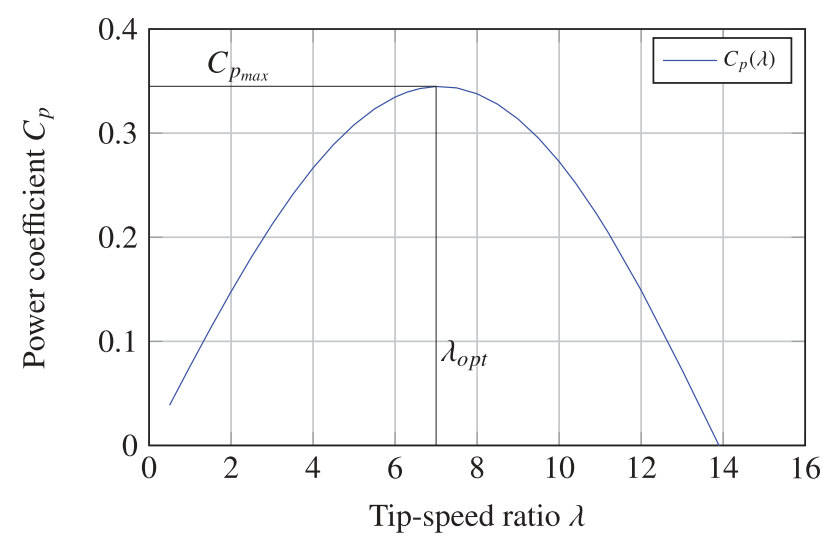

(a) Power coefficient $C_{p}(\lambda)$.

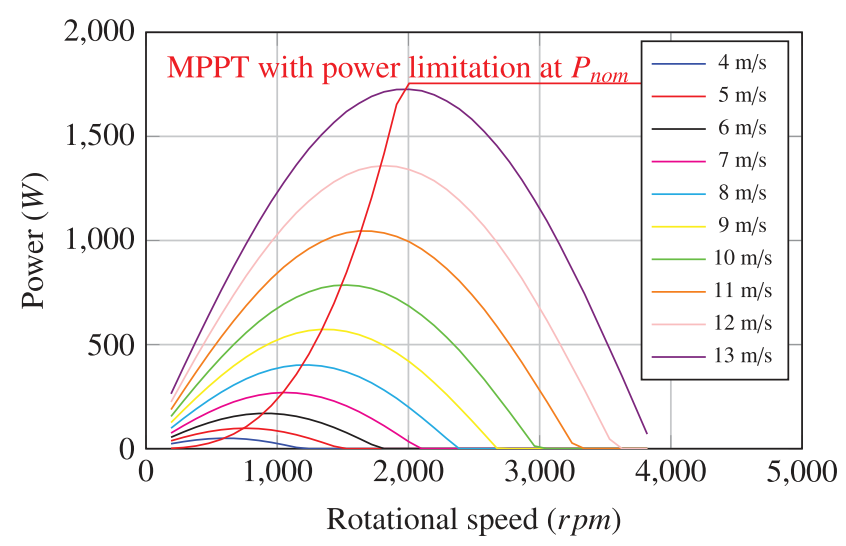

(b) Mechanical output power with respect to turbine rotational speed.

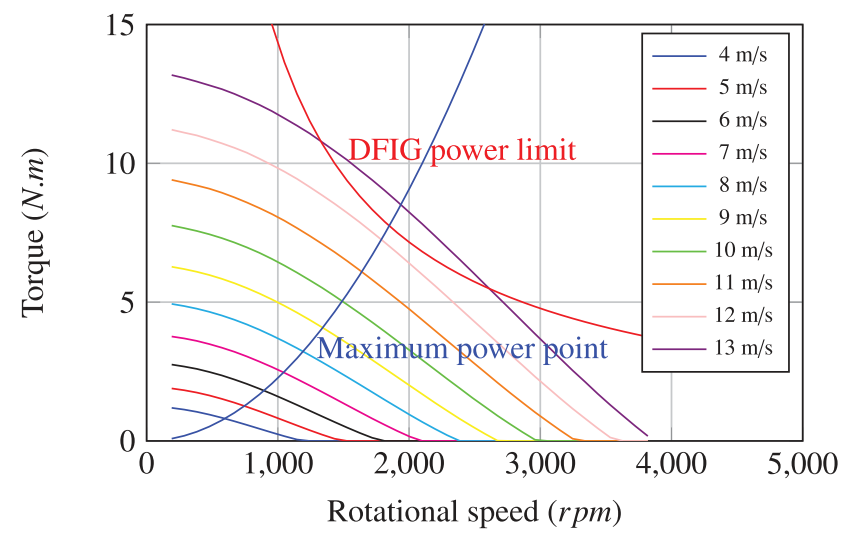

(c) Output torque with respect to turbine rotational speed.

Fig. 3. Wind turbine characteristics.

controlled based on the back-to-back converter and the DC bus. The active powers flowing through the stator $P_{s}$ and rotor $P_{r}$ of DFIG are given by

$$
P_{S}=\frac{P_{M}}{1-s} \text { and } P_{r}=-s \frac{P_{M}}{1-s}
$$

where, $P_{M}, P_{s}$, and $P_{r}$ are the DFIG mechanical, stator, and rotor active powers, respectively. The slip $s$ is defined as: $s=$ $\frac{\omega_{s}-p \Omega_{M}}{\omega_{S}}$. Neglecting losses on the back-to-back converter and the resistance of the input inductances, power balance allows 


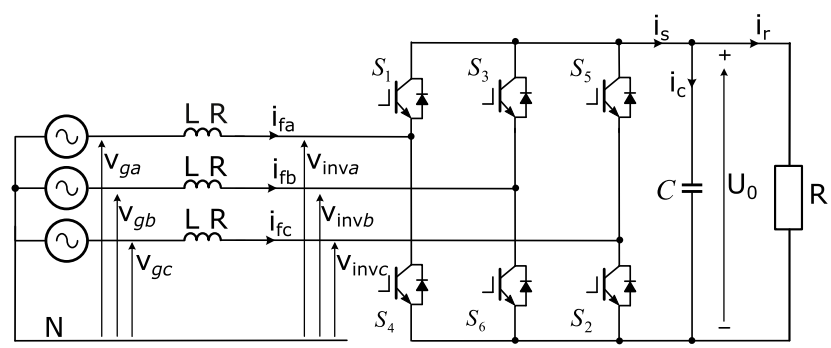

Fig. 4. Grid-side converter topology.

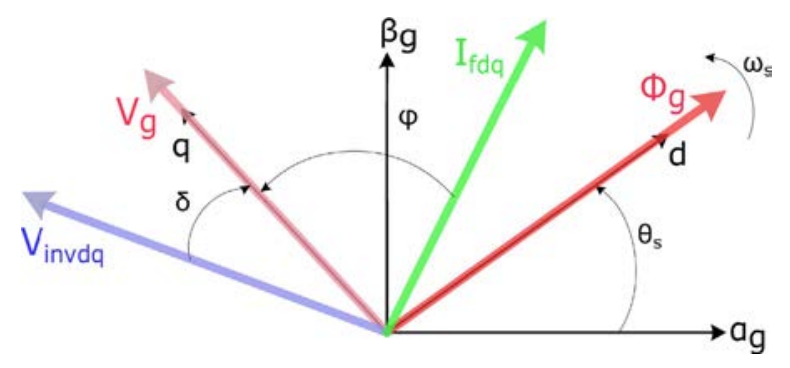

Fig. 5. Park reference frame orientation for grid-side converter control.

to write the following equation:

$$
P_{r}=P_{G S C}-P_{C}
$$

where, $P_{G S C}$ is active power at tie-line power flow injection to the main grid and $P_{C}$ is active power on DC bus capacitor given by

$$
P_{C}=\frac{d}{d t}\left(\frac{1}{2} C U_{0}^{2}(t)\right)=C U_{0}(t) \frac{d U_{0}(t)}{d t}
$$

The DC bus voltage $U_{0}(t)$ is the sum of DC component $U_{0}$ and varying component $\tilde{U}_{0}(t)$ in steady-state, i.e:

$$
U_{0}(t)=U_{0}+\tilde{U}_{0}(t) \text {. }
$$

Using the former expression and neglecting second-order terms leads to the following expression:

$$
P_{C}=P_{G S C}-P_{r} \approx C U_{0} \frac{d \tilde{U}_{0}(t)}{d t}
$$

Let us note, $\tilde{U}_{0_{\text {reg }}}=\frac{P_{G S C}-P_{r}}{U_{0}}$. Hence, the open-loop transfer function allowing to compute the DC bus voltage PI-regulator parameters is given by:

$$
H_{u}(\mathfrak{s})=\frac{1}{C \mathfrak{s}} \times K_{p_{u}}\left(1+\frac{1}{\tau_{i_{u}} \mathfrak{s}}\right)
$$

Regulator parameters $K_{p_{u}}$ and $\tau_{i_{u}}$ are computed as follows:

$$
\left\{\begin{array}{l}
\tau_{i_{u}}=C \omega_{0}^{2} \\
K_{p_{u}}=2 \xi C \omega_{0}
\end{array}\right.
$$

where, $\xi$ corresponds to selected damping ratio and $\omega_{0}=\frac{3}{T_{T_{u}}}$ (for $\xi=\frac{\sqrt{2}}{2}$ ) denotes the chosen natural frequency. Parameter $T_{r_{u}}$ corresponds to chosen voltage time-response (generally, $T_{r_{u}} \geq 10 T_{r_{i}}$ ).

Finally, the overall control scheme of the grid-side converter is given by Fig. 6 . The feedback controls consist of:

- Inner currents loops to control the $d$ - and $q$ - axis currents;

- Outer voltage loop to control the DC bus voltage $U_{0}$ and the active and reactive powers flow;

- Modulation, which is a carrier-based PWM to control the inverter six switches;

- $\mathrm{abc} / \mathrm{dq}$ and $\mathrm{dq} / \mathrm{abc}$ transformations, which transform variables from stationary frame to synchronous one, and vice-versa;

- Phase-Locked Loop (PLL) for grid voltage angle $\theta_{s}$ computation. The PLL is achieved based on the principle depicted by Fig. 7. Note that $\theta_{s}$ is estimated based on the measurement of phase-to-phase voltages in order to get rid of homopolar components (multiples of the $3^{\text {rd }}$ harmonic);

- Decoupling: $d q$ axes variables are decoupled since $d$-axis current is a function of both $d$ - and $q$-axis variables, so is the $q$-axis current. 


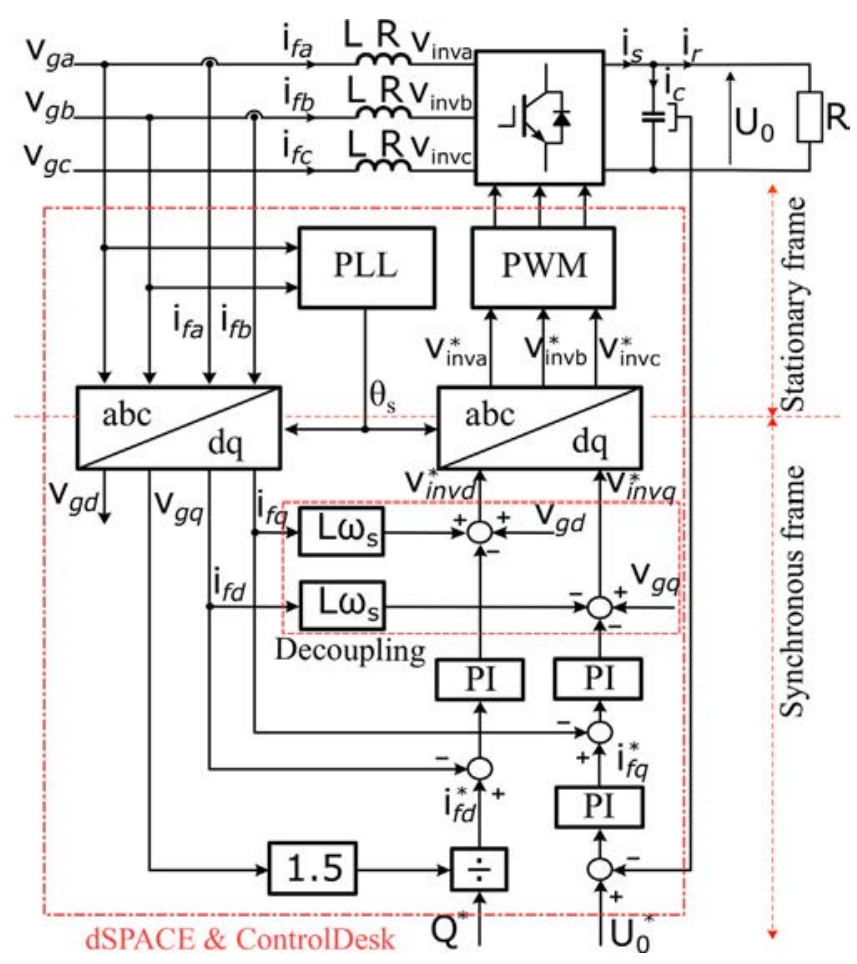

Fig. 6. Grid-side converter control: voltage oriented control (VOC).

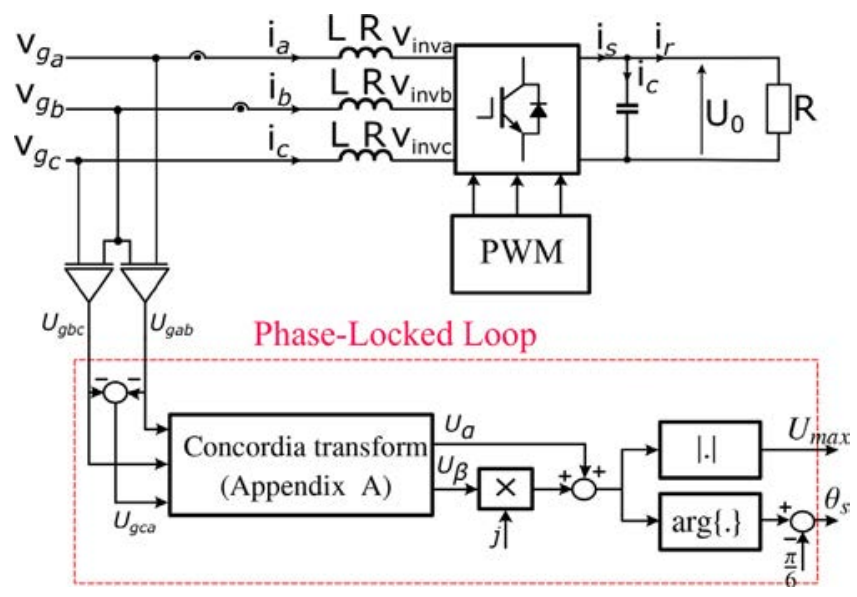

Fig. 7. PLL based on phase-to-phase voltages.

3.1.2. Active and reactive powers management

Based on the previously chosen $d q$ reference frame orientation, active and reactive powers can be calculated as follows:

$$
\left\{\begin{array}{l}
P_{G S C}=\frac{3}{2}\left(V_{g d} i_{f d}+V_{g q} i_{f q}\right)=\frac{3}{2} V_{g q} i_{f q} \\
Q_{G S C}=\frac{3}{2}\left(V_{g q} i_{f d}-V_{g d} i_{f q}\right)=\frac{3}{2} V_{g q} i_{f d}
\end{array}\right.
$$

Consequently, the $d$-axis current reference, termed as reactive component of the line (grid) current, can be calculated by

$$
i_{f d}^{*}=\frac{Q_{G S C}^{*}}{1.5 * V_{g q}}
$$




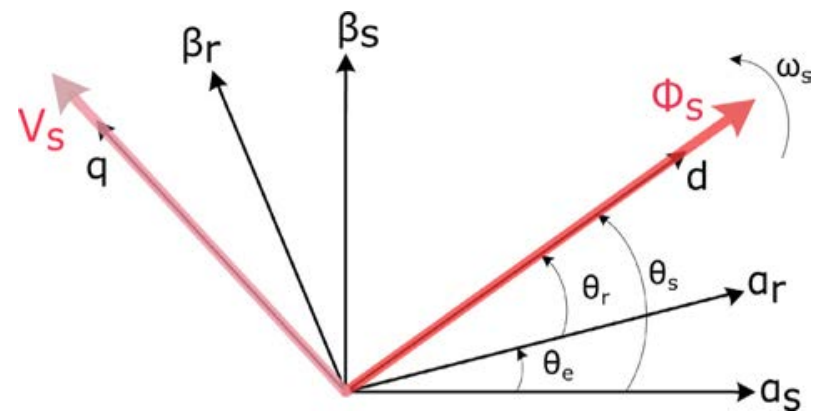

Fig. 8. Park reference frame orientation for generator-side converter control $\left(V_{s d}=0 \mathrm{~V}\right.$ only if $\left.R_{s}=0\right)$.

\subsection{Generator-side converter}

\subsubsection{DFIG modeling}

The DFIG stator and rotor windings are star-coupled without neutral connection. DFIG modeling is based on the following assumptions:

- Negligible saturation, infinite iron permeability, and non-conductive magnetic circuit;

- Constant airgap (neglecting the slotting effects);

- Sinusoidal spatial distribution of the airgap flux.

Based on these simplifying assumptions, DFIG stator and rotor voltages in the $d q$ reference frame are described by (23). In this equation, the $d$ - and $q$-axis fluxes are given by:

$$
\begin{aligned}
& {\left[\begin{array}{l}
V_{s d} \\
V_{s q} \\
V_{r d} \\
V_{r q}
\end{array}\right]=\left[\begin{array}{cccc}
R_{s} & 0 & 0 & 0 \\
0 & R_{s} & 0 & 0 \\
0 & 0 & R_{r} & 0 \\
0 & 0 & 0 & R_{r}
\end{array}\right]\left[\begin{array}{l}
I_{s d} \\
I_{s q} \\
I_{r d} \\
I_{r q}
\end{array}\right]+\frac{d}{d t}\left[\begin{array}{c}
\Phi_{s d} \\
\Phi_{s q} \\
\Phi_{r d} \\
\Phi_{r q}
\end{array}\right]+\left[\begin{array}{cccc}
-\omega_{s} & 0 & 0 & 0 \\
0 & \omega_{s} & 0 & 0 \\
0 & 0 & -\omega_{r} & 0 \\
0 & 0 & 0 & \omega_{r}
\end{array}\right]\left[\begin{array}{c}
\Phi_{s d} \\
\Phi_{s q} \\
\Phi_{r d} \\
\Phi_{r q}
\end{array}\right]} \\
& {\left[\begin{array}{c}
\Phi_{s d} \\
\Phi_{s q} \\
\Phi_{r d} \\
\Phi_{r q}
\end{array}\right]=\left[\begin{array}{cccc}
L_{s} & 0 & M_{0} & 0 \\
0 & L_{s} & 0 & M_{0} \\
M_{0} & 0 & L_{r} & 0 \\
0 & M_{0} & 0 & L_{r}
\end{array}\right]\left[\begin{array}{c}
I_{s d} \\
I_{s q} \\
I_{r d} \\
I_{r q}
\end{array}\right]}
\end{aligned}
$$

where, $R_{S}$ is the stator windings resistance and $R_{r}$ is the rotor windings resistance. $L_{s}=l_{s}-m_{s}$ and $L_{r}=l_{r}-m_{r}$ are cyclic stator and rotor inductances, respectively. $M_{0}=\frac{2}{3} m_{s r}$ is cyclic mutual inductance between stator and rotor windings. Moreover, $l_{s}$ is the self-inductance of stator windings, $l_{r}$ is the self-inductance of rotor windings, $m_{s}$ is the mutual inductance between two stator windings, $m_{r}$ is the mutual inductance between two rotor windings, $m_{s r}$ is the maximum mutual inductance between rotor and stator windings and vice-versa. Note that Park transform for rotor variables (currents and voltages) is performed using $\theta_{r}$ the currents/voltages angle, which is given by:

$$
\left\{\begin{array}{l}
\theta_{r}=\theta_{s}-\theta_{e}=\theta_{s}-p \theta_{m}, \\
\omega_{s}=\omega_{r}+p \Omega_{M} .
\end{array}\right.
$$

Nonetheless, Park transform for stator variables is performed using $\theta_{s}$ estimated based on the previously discussed PLL. Moreover, for this study, the chosen Park transform is the amplitudes-invariant form (see Appendix A).

DFIG stator is directly connected to the main grid through a transformer (see Fig. 1), which imposes its own voltage amplitude and frequency ( $50 \mathrm{~Hz}$ in Europe). Hence, the stator flux is fixed in steady-state conditions. To simplify previous equations, the $d$-axis of the Park reference frame is aligned with the stator flux. The stator voltage is consequently aligned along the $q$-axis as depicted by Fig. 8. This Park reference frame orientation implies the following simplifications:

$$
\begin{aligned}
& \Phi_{s d}=\Phi_{s} \frac{d \Phi_{s d}}{d t}=0 \Phi_{s q}=0 \frac{d \Phi_{s q}}{d t}=0 \\
& V_{s d}=0 V_{s q}=\omega_{s} \Phi_{s d} \Rightarrow V_{s q}=V_{s}=\omega_{s} \Phi_{s}
\end{aligned}
$$

Straightforward computations allow to express $I_{s q}$ as function of $I_{r q}$ as follows:

$$
I_{s q}=-\left(\frac{M_{0}}{L_{s}}\right) I_{r q}
$$

Based on the previous computations, the DFIG electromagnetic torque is given by:

$$
\Gamma_{e m}=\frac{3}{2} p\left(\Phi_{s d} I_{s q}-\Phi_{s q} I_{s d}\right)
$$




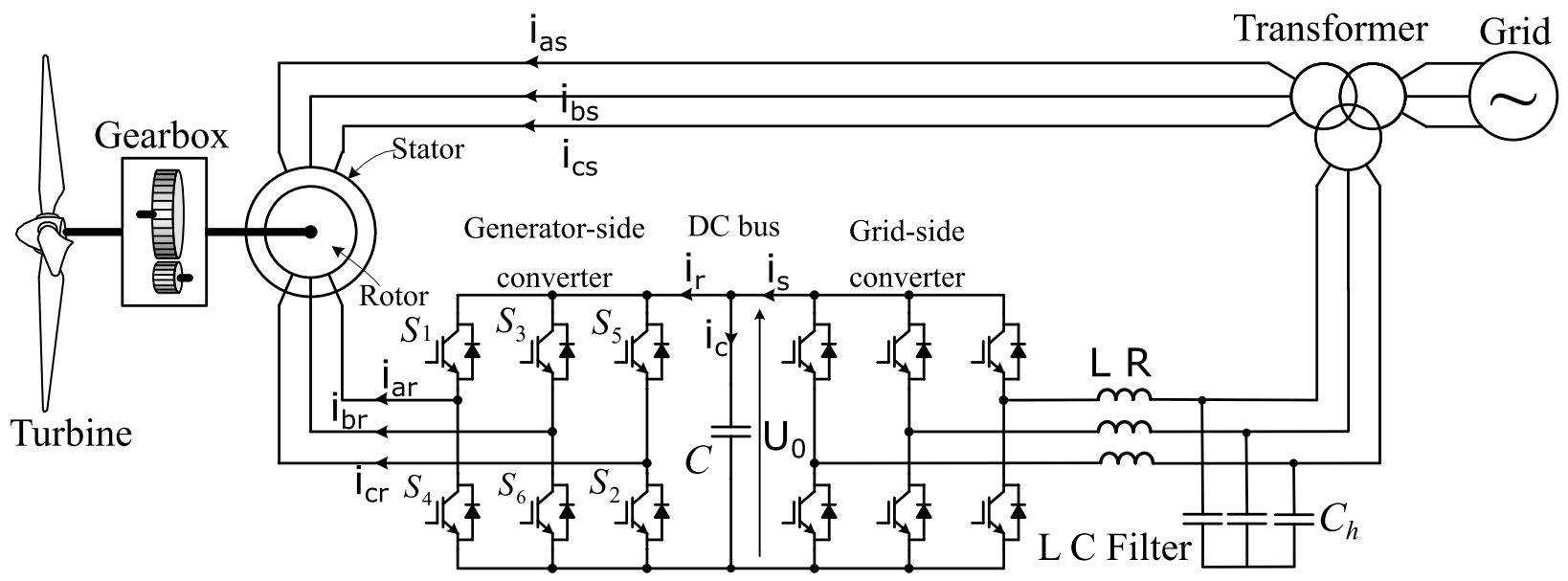

Fig. 9. Generator-side converter topology.

$$
\begin{aligned}
& =\frac{3}{2} p\left(\Phi_{s d}\left(-\frac{M_{0}}{L_{s}}\right)\right) I_{r q} \\
& =-\frac{3}{2} p\left(\frac{V_{s} M_{0}}{L_{s} \omega_{s}}\right) I_{r q}
\end{aligned}
$$

The active and reactive powers of the stator and rotor of DFIG are given by the following formulas:

$$
\left\{\begin{array}{l}
P_{s}=\frac{3}{2}\left(V_{s d} I_{s d}+V_{s q} I_{s q}\right)=\frac{3}{2} V_{s q} I_{s q}=-\frac{3}{2} V_{s}\left(\frac{M_{0}}{L_{s}}\right) I_{r q} \\
Q_{s}=\frac{3}{2}\left(V_{s q} I_{s d}-V_{s d} I_{s q}\right)=\frac{3}{2} V_{s q} I_{s d}=\frac{3}{2}\left(\frac{V_{s}^{2}}{L_{s} \omega_{s}}-\frac{V_{s} M_{0}}{L_{s}} I_{r d}\right) \\
P_{r}=\frac{3}{2}\left(V_{r d} I_{r d}+V_{r q} I_{r q}\right) \\
Q_{r}=\frac{3}{2}\left(V_{r q} I_{r d}-V_{r d} I_{r q}\right)
\end{array}\right.
$$

The link between torque and active power shows the energy production. In fact, controlling $I_{r q}$ in order to get a negative electromagnetic torque (opposite torque of the turbine torque) allows to have a negative stator active power (generator). These equations leads to the following conclusions:

- Stator active power and DFIG electromagnetic torque control can be achieved through the control of rotor quadratic current $I_{r q}$;

- Stator reactive power control can be achieved through the control of rotor direct current $I_{r d}$.

Finally, the motion equation of the high-speed shaft is governed by the following law:

$$
\frac{d \Omega_{M}}{d t}=\frac{\Gamma_{T}\left(\Omega_{M}, v_{w}\right)}{G_{r} J_{t}}-\frac{\Gamma_{e m}+f_{v} \Omega_{M}+\Gamma_{s}}{J_{t}}
$$

where $J_{t}$ corresponds to the total rotating components inertia, $f_{v}$ is the viscous friction coefficient, $\Gamma_{s}$ is the dry friction torque, and $\Gamma_{T}\left(\Omega_{M}, v_{w}\right)$ is the turbine torque, which is related to the harvested power as follows

$$
\Gamma_{T}\left(\Omega_{M}, v_{w}\right)=\frac{P_{T}}{\Omega_{T}}=\frac{1}{2} \pi R_{T}^{3} C_{\Gamma}(\lambda) v_{w}^{2}
$$

with, $C_{\Gamma}(\lambda)=\frac{C_{p}(\lambda)}{\lambda}$ is the torque coefficient.

\subsubsection{Rotor-side converter topology and control}

Generator-side converter topology, which is used as a fully-controlled rectifier, is given by Fig. 9. All mid-points of each rectifier legs are connected to DFIG rotor windings. In this case, a PWM is used to control rotor currents. A straightforward computations based on (23) allow to express the DFIG $d$ - and $q$-axis rotor voltages as follows:

$$
\left\{\begin{array}{l}
V_{r d}=R_{r} I_{r d}+\sigma L_{r} \frac{d I_{r d}}{d t}-\omega_{r} \sigma L_{r} I_{r q} \\
V_{r q}=R_{r} I_{r q}+\sigma L_{r} \frac{d I_{r q}}{d t}+\omega_{r} \sigma L_{r} I_{r d}+\omega_{r} \frac{M_{0} V_{s}}{\omega_{s} L_{s}}
\end{array}\right.
$$

where $\sigma=1-\frac{M_{0}^{2}}{L_{r} L_{S}}$ is Blondel's dispersion coefficient. 
Similarly to the study of grid-side converter, these expressions show that there is coupling terms that must be compensated. Let us consider

$$
\left\{\begin{array}{l}
V_{r d_{r e g}}=V_{r d}^{*}+\omega_{r} \sigma L_{r} I_{r q} \\
V_{r q_{r e g}}=V_{r q}^{*}-\omega_{r} \sigma L_{r} I_{r d}-\omega_{r} \frac{M_{0} V_{s}}{\omega_{s} L_{s}}
\end{array}\right.
$$

This leads to the following decoupled equations

$$
\left\{\begin{array}{l}
V_{r d_{r e g}}=R_{r} I_{r d}+\sigma L_{r} \frac{d I_{r d}}{d t} \\
V_{r q_{r e g}}=R_{r} I_{r q}+\sigma L_{r} \frac{d I_{r q}}{d t}
\end{array}\right.
$$

Hence, the open-loop transfer function, which allows computing the PI-regulators parameters, is given by:

$$
H_{i r}(\mathfrak{s})=\frac{I_{r d q}}{V_{r d q_{r e g}}}=-\frac{\frac{1}{R_{r}}}{1+\frac{\sigma L_{r}}{R_{r}} \mathfrak{s}} \times K_{p_{i r}}\left(1+\frac{1}{\tau_{i_{i r}} \mathfrak{s}}\right)
$$

The currents PI-regulators parameters $K_{p_{i r}}$ and $\tau_{i_{i r}}$ are computed for the $d q$ axes as follows:

$$
\left\{\begin{array}{l}
\tau_{i_{i r}}=\frac{\sigma L_{r}}{R_{r}} \\
K_{p_{i r}}=\frac{3 \sigma L_{r}}{T_{r_{i}}}
\end{array}\right.
$$

where $T_{r_{i}}$ corresponds to the required currents time-response (time to achieve $95 \%$ of final value).

Fig. 10 depicts the overall control scheme of the generator-side converter. The $d$ - and $q$-axis currents are used to control the stator active and reactive powers flow and are given by the following expressions:

$$
\left\{\begin{array}{l}
I_{r q}^{*}=-\left(\frac{L_{s} \omega_{s}}{p M_{0} V_{s}}\right) \Gamma_{e m}^{*} \\
I_{r d}^{*}=\frac{V_{s}}{M_{0} \omega_{s}}-\frac{L_{s}}{V_{s} M_{0}} Q_{s}^{*}
\end{array}\right.
$$

where, $\Gamma_{e m}^{*}$ and $Q_{s}^{*}$ correspond to DFIG electromagnetic torque and stator reactive power references, respectively. The DFIG electromagnetic torque reference $\Gamma_{e m}^{*}$ is determined in order to achieve maximum active power extraction (MPPT). MPPT by optimal torque control is implemented. A straightforward manipulations lead to the following expression of the electromagnetic torque reference:

$$
\Gamma_{e m}^{*}=K_{o p t} \Omega_{M}^{2}
$$

where, $K_{o p t}$ is a parameter characterizing the wind turbine given by:

$$
K_{o p t}=\frac{\pi R_{T}^{5} \rho C_{p_{\max }}}{2 G_{r}^{3} \lambda_{o p t}^{3}}
$$

\section{3. $L C$ filter, DC bus, and transformer sizing}

\subsection{1. $L C$ filter and $D C$ bus capacitor}

In [22], the authors have described a methodology for filtering inductor, switching frequency, DC bus, and filtering capacitor design in order to better meet the required specifications. In this study, the DC bus voltage (ignoring IGBT switches dead-time effect) is given by:

$$
U_{0} \geq \frac{2}{R_{\text {inv } \max }} \sqrt{V_{g}^{2}+\left(L \omega_{s} I_{f}\right)^{2}}
$$

where $R_{i n v_{\max }}$ is the maximal value of duty cycle (in general, $\left.R_{i n v_{\max }}=0.95\right), V_{g}$ is the grid voltage root mean square (RMS) value, and $I_{f}$ is the line current RMS value.

The expression allowing the inductor sizing is as follows:

$$
L \geq \frac{U_{0}}{6.9 \Delta i_{f_{\max }} F_{s w}}
$$

where $\Delta i_{f_{\max }}$ is the required line current ripple (5\% for instance) and $F_{s w}$ corresponds to the fixed switching frequency.

Finally, the expression allowing the DC bus capacitor sizing is as follows

$$
C \geq\left|\Delta i_{r}\right| \frac{4}{\Delta U_{0_{\max }} \omega_{b w}^{u} \sqrt{5}} e^{-\frac{\pi}{2} \sqrt{\frac{3}{2}}}
$$

where $\Delta i_{r}$ corresponds to the load maximal current variation (generally, $\left.50 \%\right), \Delta U_{0_{\max }}$ is the allowed DC bus voltage ripple, and $\omega_{b w}^{u}$ is the bandwidth of the voltage loop $\left(\omega_{b w}^{u}=10 \mathrm{~Hz}\right.$, for instance). 


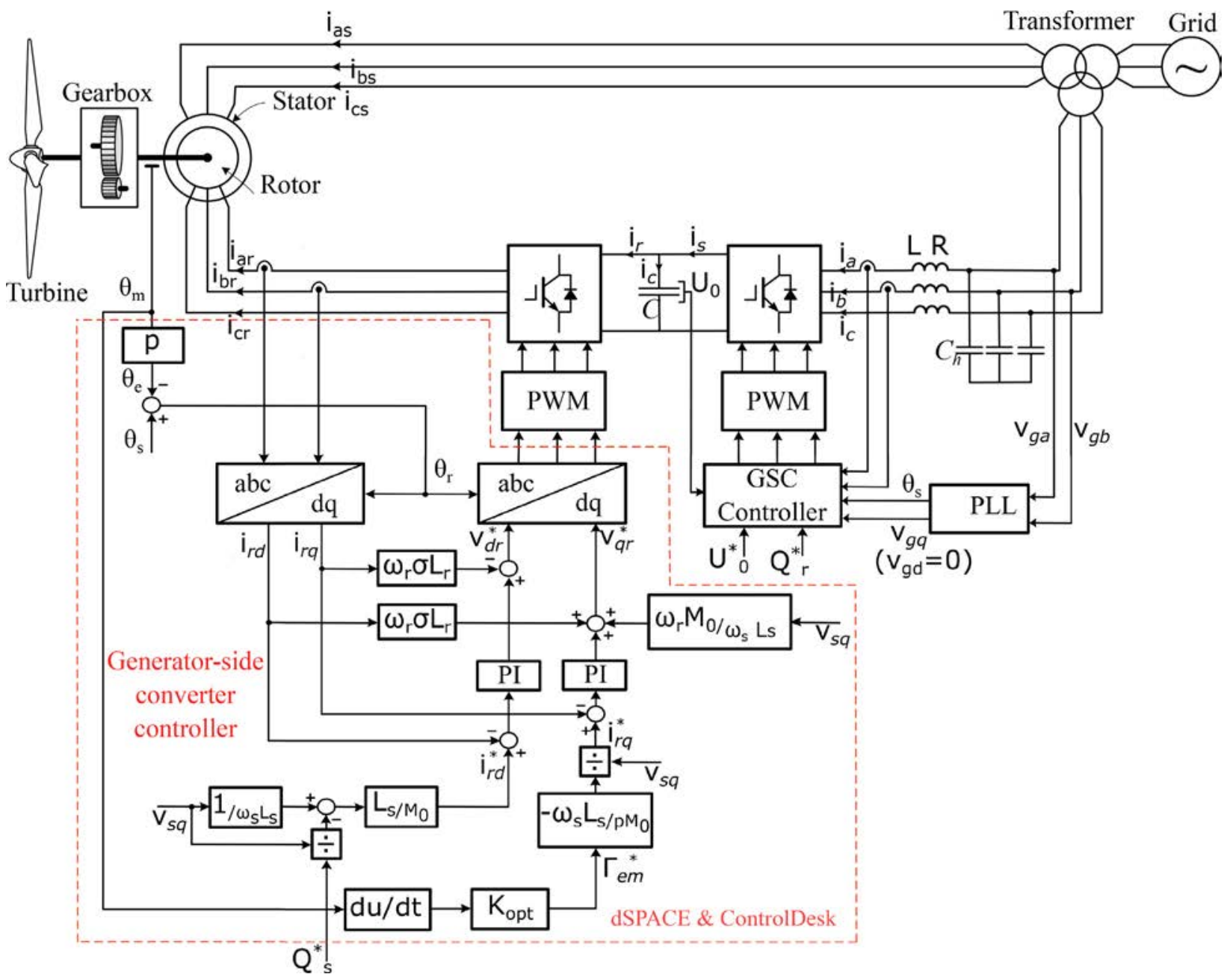

Fig. 10. Generator-side converter control strategy based on MPPT.

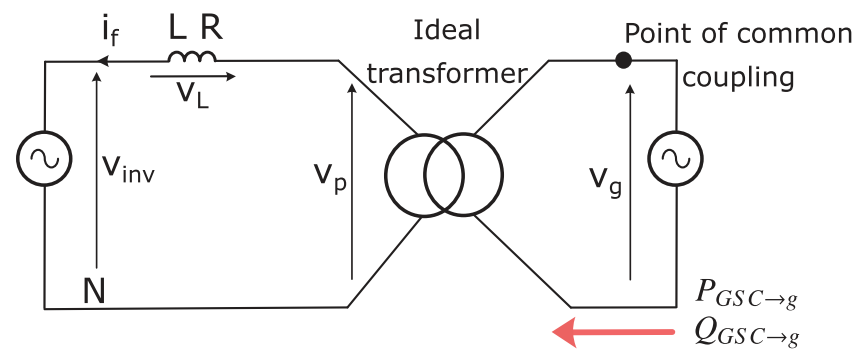

Fig. 11. Single-phase scheme of GSC output, filter, transformer and grid.

\subsubsection{Transformer}

The RMS value of the output voltage of the grid-side converter is given by

$$
V_{i n v_{e f f}}=\frac{U_{0}}{2 \sqrt{2}} R_{i n v} \quad \text { avec } \quad 0 \leq R_{\text {inv }} \leq 1
$$

The DC bus voltage is generally limited to maximum value $U_{0_{\max }}$ and knowing that $R_{\text {inv }}$ is limited to 0.95 for security reasons, $V_{i n v_{e f f}}$ is limited to maximum value $V_{i n v_{\text {ef } \max }}=\frac{0.95}{2 \sqrt{2}} U_{0_{\max }}$. This value is generally lower than grid voltage RMS value $V_{g}$. Consequently, a step-up power transformer is necessary to interface the low-voltage rotor wind generator to the power grid. The scheme given by Fig. 11 shows the interface transformer and allows transformer sizing (voltage on primary windings $V_{p}$, knowing the secondary voltage that is grid voltage $V_{g}$ ). 
Let us consider ideal transformer and neglect the equivalent resistance of the inductor. Furthermore, let us note $P_{G S C} \rightarrow g$ and $Q_{G S C} \rightarrow g$ the active and reactive powers at the point of common coupling (PCC), respectively. These powers are given by:

$$
\left\{\begin{array}{l}
P_{G S C \rightarrow g}=P_{G S C} \\
Q_{G S C \rightarrow g}=Q_{G S C}+3 L \omega_{s} I_{f}^{2}
\end{array}\right.
$$

where, $I_{f}$ corresponds to RMS value of the inductor current.

The transformer sizing is performed for the worst case. In super-synchronous mode, the rotor provides active power at rated wind turbine speed. In this case, the DFIG rotational speed is $204 \mathrm{rad} / \mathrm{s}$ and its stator active power (without mechanical losses) is equal to nominal power $P_{S_{\max }}=P_{S_{\text {nom }}}$. Neglecting Joule losses in the rotor and considering the slip value $s=-30 \%$, the maximal rotor active power is $P_{r_{\max }}$. Neglecting power converters losses, this power is equal to power at PCC.

$$
\left\{\begin{array}{l}
P_{G S C}=P_{r_{\max }} \\
Q_{G S C}=Q_{G S C \rightarrow g}-3 L \omega_{S} I_{f}^{2} \\
S_{G S C}=3 V_{i n v} I_{f}=\sqrt{P_{G S C}^{2}+Q_{G S C}^{2}}
\end{array}\right.
$$

where, $Q_{G S C} \rightarrow g$ is the fixed reactive power injection in order to participate to system services. The apparent power $S_{G S C}$ expression allows to compute the RMS value of line current $I_{f}$. Hence, the apparent power provided to the grid at PCC allows to calculate the primary windings voltage of the used transformer as follows:

$$
S_{G S C \rightarrow g}=3 V_{p} I_{f}=\sqrt{P_{G S C \rightarrow g}^{2}+Q_{G S C \rightarrow g}^{2}}
$$

Finally, $V_{p}$ is given by:

$$
V_{p}=\frac{\sqrt{P_{G S C \rightarrow g}^{2}+Q_{G S C \rightarrow g}^{2}}}{3 I_{f}}
$$

\section{Experimental platform}

The experimental platform has been designed using a $1.5 \mathrm{~kW}$ test-rig composed of DFIG connected to the utility grid through a back-to-back converter and a transformer and driven by a DC motor. The DC motor is used for emulating the turbine. The achieved emulator enables accurate dynamic reproduction behavior of real WEC under deterministic and realistic conditions. The back-to-back converter is controlled based on DS1104 controller board from dSPACE and real-time parameters tuning is performed based on ControlDesk application. Section 4.1 is dedicated to the description of the test-rig and digital control implementation, while Sections 4.2 and 4.3 present the grid-side converter and generator-side converter experimental results. Finally, Section 4.4 describes the experimental results for the overall system.

\subsection{Laboratory test-rig}

\subsubsection{Setup description}

Fig. 12 shows the experimental setup overall scheme. A laboratory prototype equipped with a $1.5 \mathrm{~kW}$ DFIG was built for validation. Experiments were conducted on the test-rig shown by Fig. 13. The experimental bench consists of a threephase wounded-rotor induction machine coupled to a DC motor. The induction machine has two pole pairs and a nominal torque of $10 \mathrm{~N} . \mathrm{m}$. The back-to-back converter is composed of two SEMIKRON three-phase converters, which are controlled based on dSPACE hardware/solfware. These converters are connected to induction machine rotor and controlled by $10 \mathrm{kHz}$ PWM signals issued from the dSPACE connector panel CP1104 (CLP 1104). The DC bus voltage is achieved after rectifying the three-phase utility AC supply voltage using the grid-side converter. The connection to the main grid is achieved through three $L=5 \mathrm{mH}$ inductors for line currents smoothing and three-phase auto-transformer. All experimental setup parameters are given byAppendix $\mathrm{B}$.

The DC motor is mechanically coupled to the induction motor shaft in order to emulate the turbine behavior. The DC motor with separate excitation is fed by a three-phase diode bridge, which allows controlling the rotor speed through the DC voltage applied to the rotor.

\subsubsection{Digital control based on dSPACE board}

The whole control strategy has been implemented using a digital signal processor for applied and control engineering. Indeed, control laws have been implemented on the DS1104 controller board by dSPACE plugged in a computer as shown by Figs. 14 and 15a. The induction machine stator and rotor currents have been measured using closed-loop (compensated) current transducers using Hall effect sensors (Fig. 15b). All voltages measurements are performed using voltage differential transducers (Fig. 15c). All measured parameters (currents and voltages) are sampled using an acquisition card equipped with 16 bits analogue-to-digital converters (ADC) with $10 \mathrm{kHz}$ sampling frequency on dSPACE board (15 a). The $0-5 \mathrm{~V}$ PWM issued from CLP 1104 are amplified to 0 - 15 V PWM before being applied to IGBT switches. The yellow analog card 


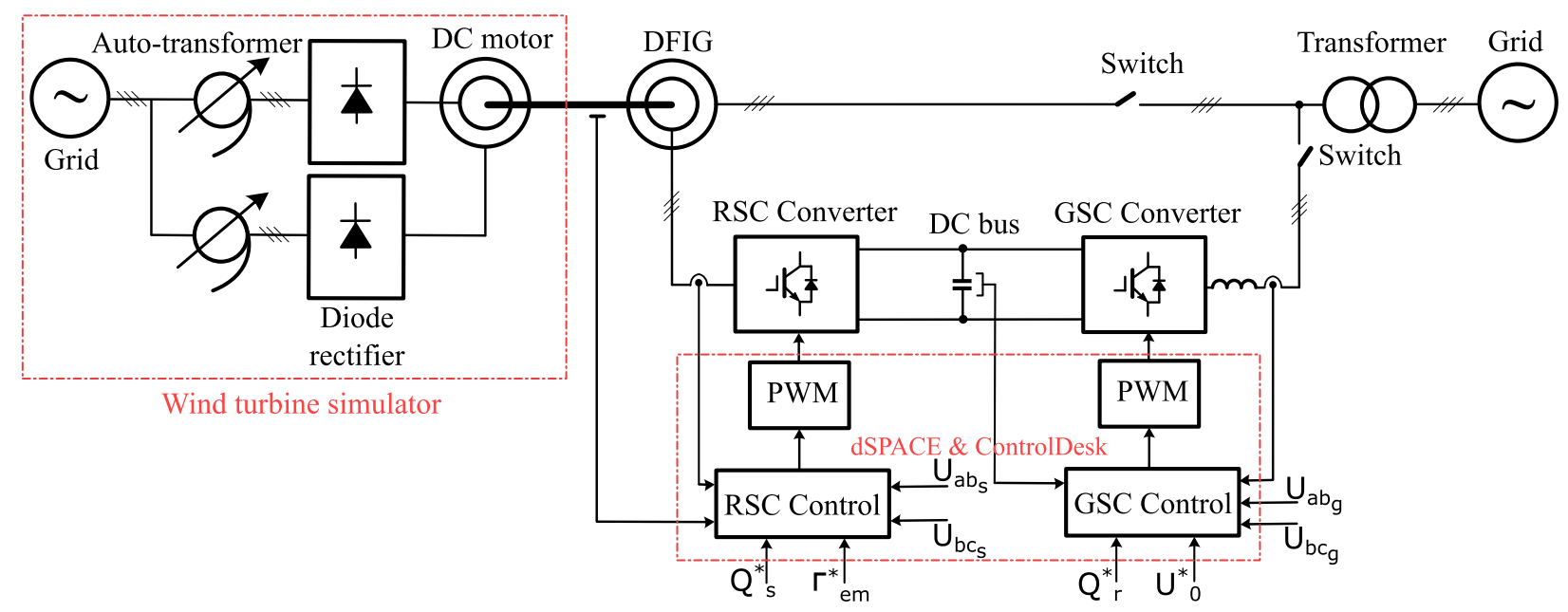

Fig. 12. Experimental setup scheme.

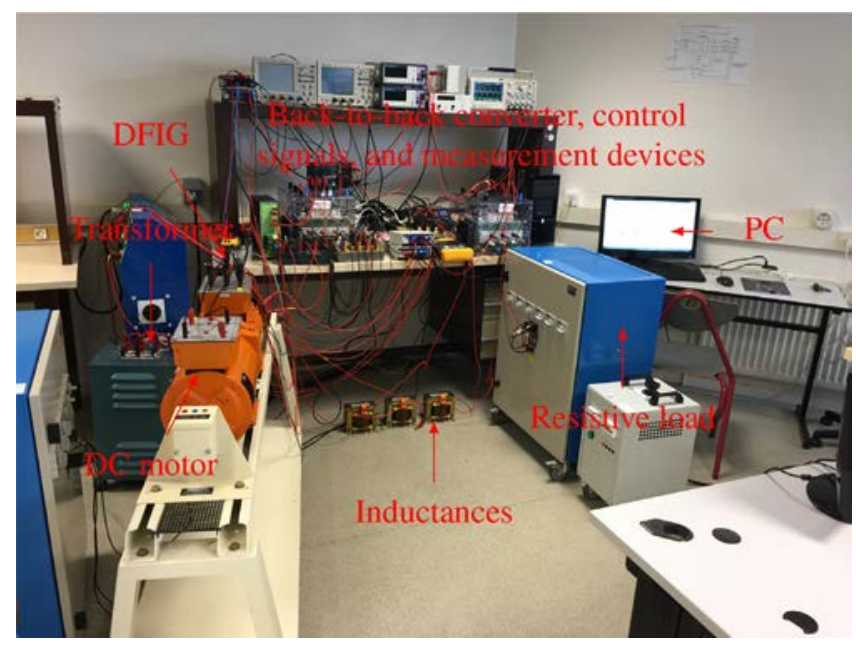

Fig. 13. Experimental platform.

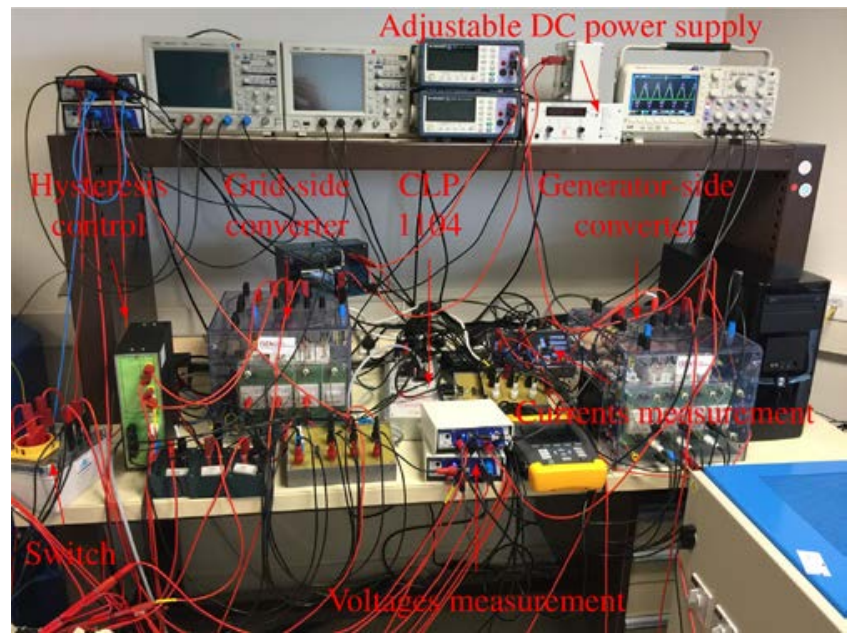

Fig. 14. Back-to-back converter control devices. 


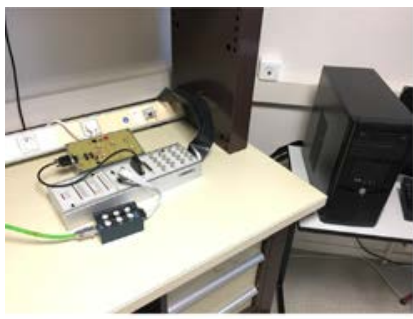

(a) CLP 1104 and PWM amplifier

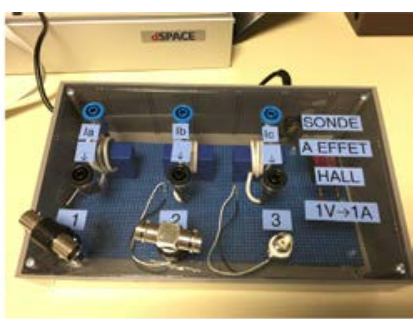

(b) Hall effect sensors.

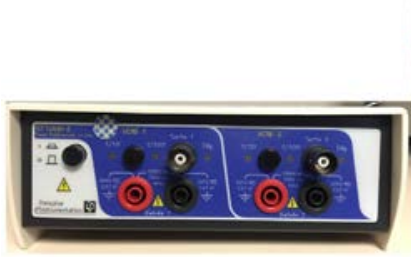

(c) Voltage differential transducers.

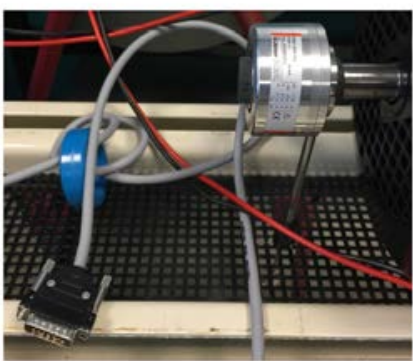

(d) Incremental encoder.

Fig. 15. dSPACE board peripherals for achieving back-to-back digital control.

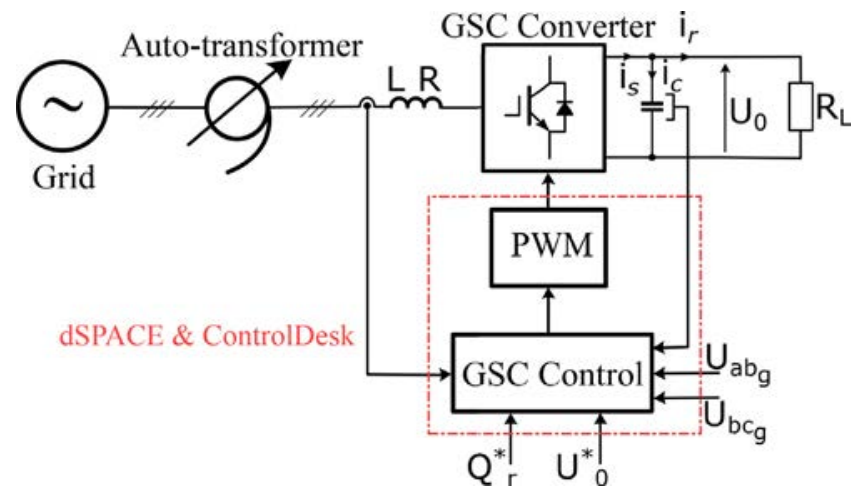

Fig. 16. Grid-side converter scheme.

in Fig. 15a shows the signal conversion module for process controlling signal conditioning (PWM amplifier). The induction machine rotor position measurement is performed using incremental encoder with 10 bits resolution as shown by Fig. $15 \mathrm{~d}$.

The whole process as shown by Fig. 12, including DFIG, DC motor, back-to-back converter, and control algorithm, has been simulated based on Matlab/Simulink software. Then, Embedded Coder has been used to generate a readable, compact and fast executable code for embedded processors and FPGA used in dSPACE hardware. This approach allows a rapid control prototyping significantly reducing the control strategy implementation for real-world applications. In the following, a stepby-step methodology is described in order to implement a DFIG-based WEC emulator on laboratory.

\subsection{Grid-side converter results}

Grid-side converter control described by Fig. 6 has been implemented using dSPACE hardware/software. For this experimental validation, the grid voltage RMS value was equal to $30 V_{r m s}$, the DC bus is controlled to maintain $U_{0}^{*}=100 \mathrm{~V}$ regardless of the load $R_{L}$. The considered load is $2 \mathrm{~kW}$ resistance with a maximum DC voltage of $U_{R L_{\max }}=220 \mathrm{~V}$. The smoothing inductance is $L=5 \mathrm{mH}$ and the DC bus capacitor is equal to $C=500 \mu \mathrm{F}$. The experimental setup scheme is given by Fig. 16. In this scheme, two grid phase-to-phase voltages $U_{a b_{g}}$ and $U_{b c g}$ are measured in order to estimate the grid angle $\theta_{s}$. Moreover, two line currents $i_{f a}$ and $i_{f b}$ are measured in order to be controlled in such way that the line currents are sinusoidal and in-phase with the corresponding phase-to-neutral voltages (no reactive power). Finally, the DC bus voltage is measured to be controlled and maintained equal to the specified reference $U_{0}^{*}$. This analysis highlights the fact that the grid-side converter allows to control the reactive power $Q_{r}$ flow through the rotor (from or to the grid) and the DC bus 


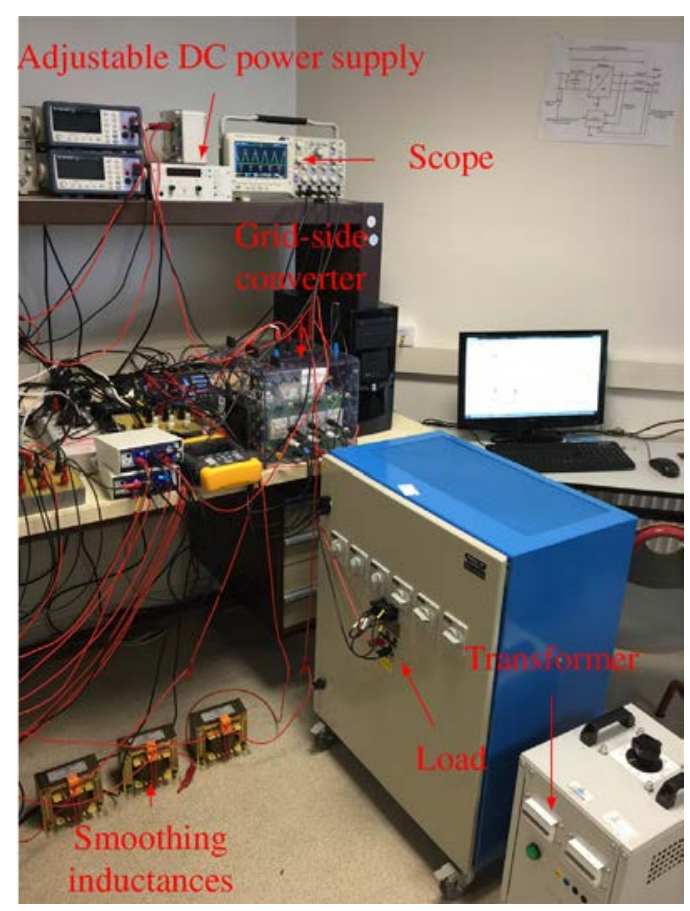

Fig. 17. Grid-side converter and transformer.

voltage $U_{0}$. Note that the control of DC voltage allows to control the active power flow to/from the grid. Fig. 17 shows the grid-side converter and transformer for the grid interface.

\subsubsection{DC bus control for several load conditions}

Fig. 18 shows the experimental results for in-phase currents and for several load conditions. The $d$-axis current is equal to zero, i.e. $i_{d}=0 \mathrm{~A}$ and the current drawn from the grid is along the $q$-axis. Therefore, no reactive power is exchanged with the grid. The DC bus is controlled to maintain a fixed voltage value equal to $U_{0}=100 \mathrm{~V}$ whatever the load conditions are. This figure shows the appropriate behavior of the currents loops since the actual current is almost equal to reference with some high frequency harmonics due to switching. Two conclusions can be drawn from this figure:

- Line currents magnitude increases when the load increases $\left(R_{L}\right.$ decreases).

- For no load $\left(R_{L}=\infty\right)$, no current is drawn from the grid as no reactive current exists.

Another experiment has been conducted to evaluate the dynamic response of the control loops. In fact, the voltage control loop performance has been assessed by increasing and decreasing the load resistance $R_{L}$. The experimental results are shown by Fig. 19. This figure clearly shows that the DC voltage control loop responds quickly to changing active power transfer to the load. In fact, for both increasing or decreasing load the control loops dynamic is appropriate for varying load, which is almost the case for WEC systems due to stochastic nature of wind speed. This allows concluding that the control strategy has a high dynamic response to varying operating conditions.

\subsubsection{Active and reactive powers control}

Fig. 20 shows experimental results for leading current and for several load conditions. In this case, the $d$-axis current is equal to $i_{d}=-4 \mathrm{~A}$. Consequently, a reactive power is injected to the grid (capacitance behavior). Fig. 21 shows the experimental results for lagging current and for several load conditions. In this case, the $d$-axis current is equal to $i_{d}=4 \mathrm{~A}$. Hence, a reactive power is absorbed from the grid (inductor behavior). For all these experiments, it can be seen that the output DC voltage $U_{0}$ is maintained constant and equal to the reference $U_{0}^{*}=100 \mathrm{~V}$. Two conclusions can be drawn from this experiment too:

- $q$-axis current controls the active power transfer to/from the grid through controlling the DC bus by maintaining its voltage constant,

- $d$-axis current controls the reactive power flow between the grid and DFIG rotor.

The DC bus of the grid-side converter will be used in the following as a DC voltage supply for the rotor-side converter and will consequently allows controlling the active and reactive powers flow between the rotor and the grid as follows:

- Sub-synchronous mode: active power transfer from the grid to DFIG rotor,

- Super-synchronous mode: active power transfer from DFIG rotor to the grid. 


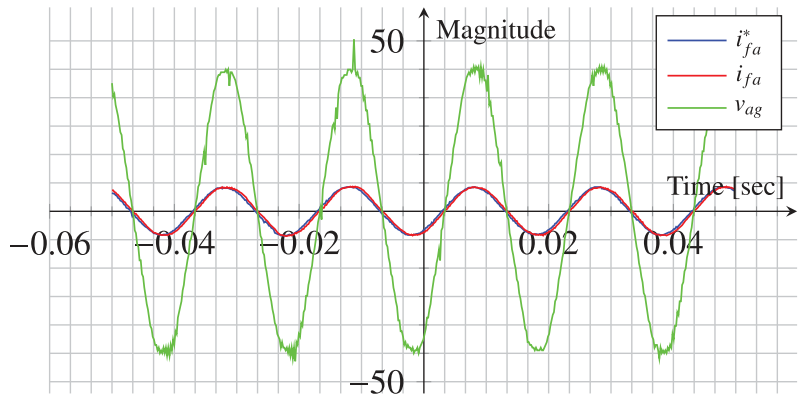

(a) Current $i_{f}$ and voltage $v_{a g}$ waveforms for full load.

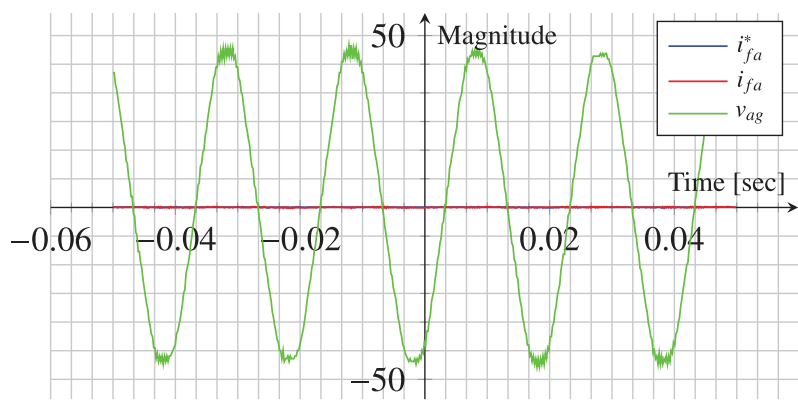

(c) Current $i_{f}$ and voltage $v_{a g}$ waveforms for no load.

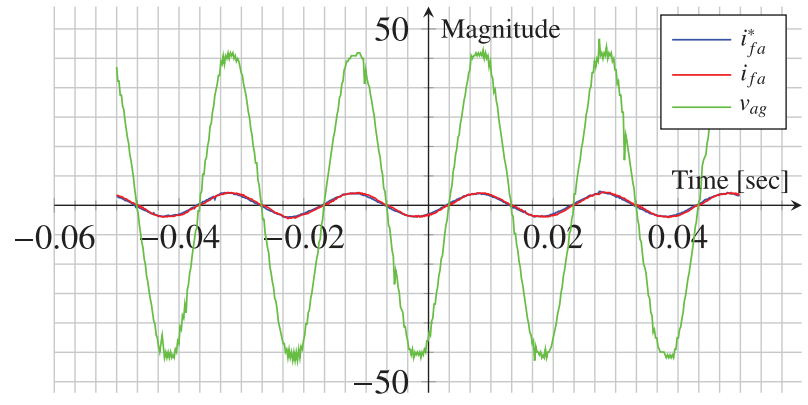

(b) Current $i_{f}$ and voltage $v_{a g}$ waveforms for half load.

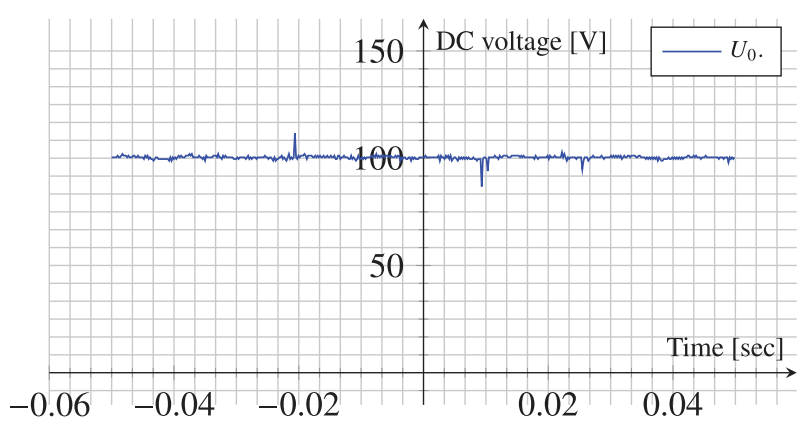

(d) DC voltage $U_{0}$.

Fig. 18. Grid-side converter results for in-phase current for several load conditions $\left(i_{d}=0 A\right)$.

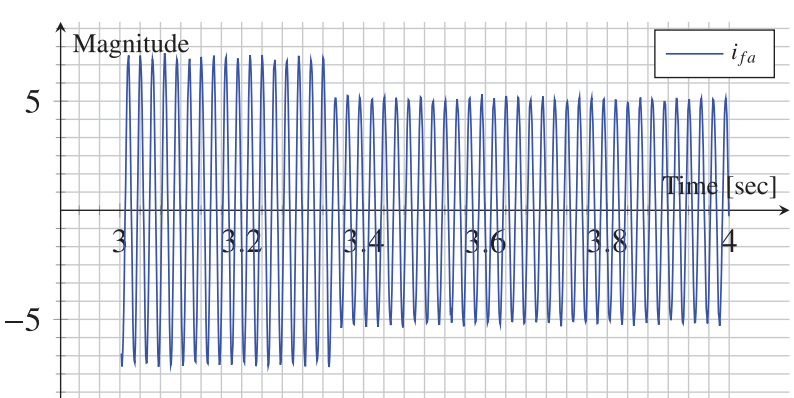

(a) Current $i_{f}$ and voltage $v_{a g}$ waveforms $\left(R_{L}: 100 \% \rightarrow 75 \%\right.$.).

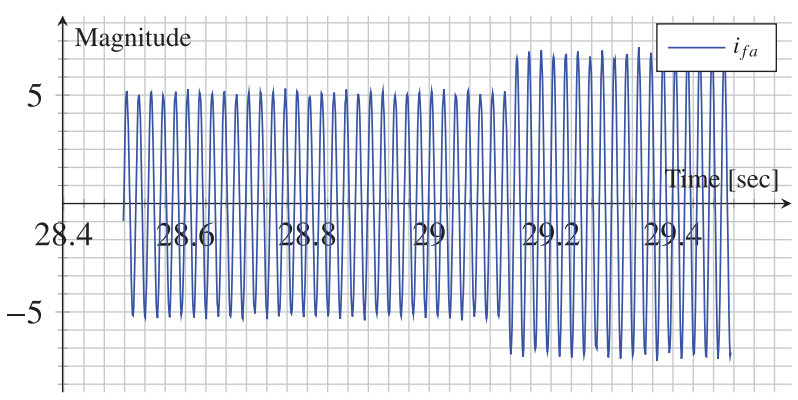

(c) Current $i_{f}$ and voltage $v_{a g}$ waveforms $\left(R_{L}: 100 \% \rightarrow 75 \%\right.$.).

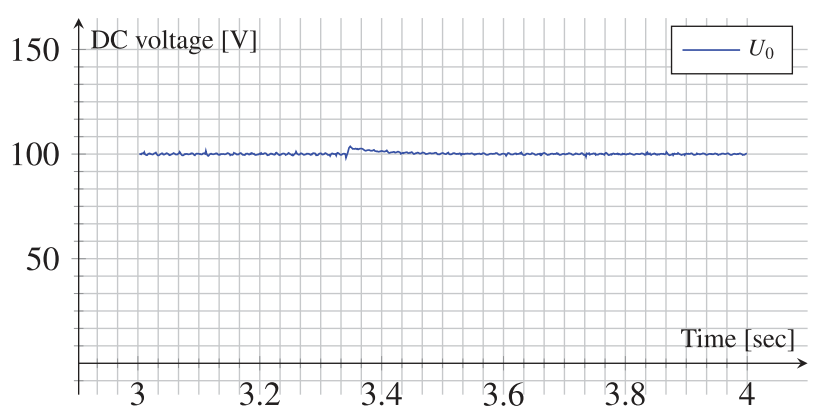

(b) DC voltage $U_{0}\left(R_{L}: 100 \% \rightarrow 75 \%\right)$.

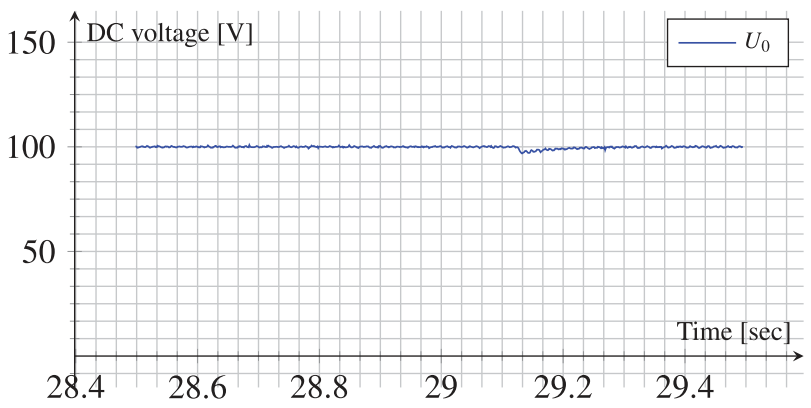

(d) DC voltage $U_{0}\left(R_{L}: 75 \% \rightarrow 100 \%\right)$.

Fig. 19. Grid-side converter experimental results: DC bus control loop dynamic performance $\left(i_{d}=0 \mathrm{~A}\right)$. 


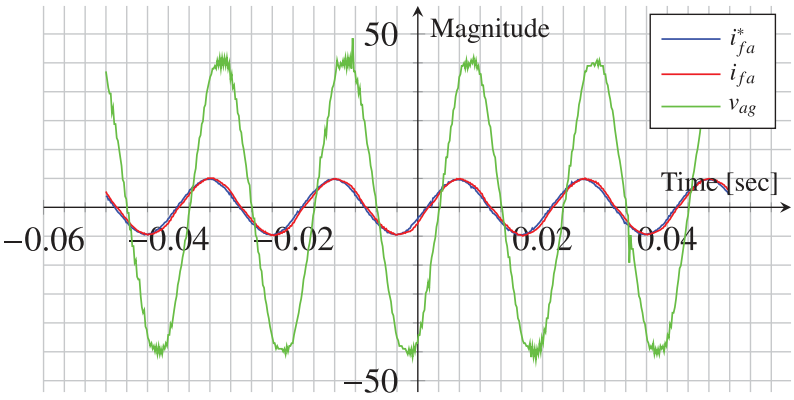

(a) Current $i_{f}$ and voltage $v_{a g}$ waveforms for full load.

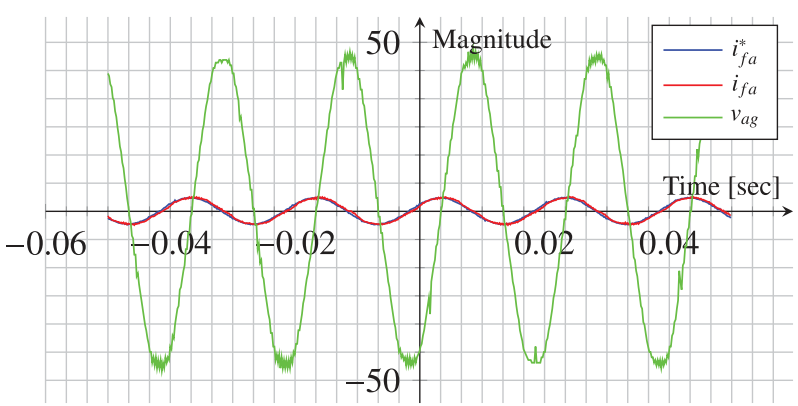

(c) Current $i_{f}$ and voltage $v_{a g}$ waveforms for no load.

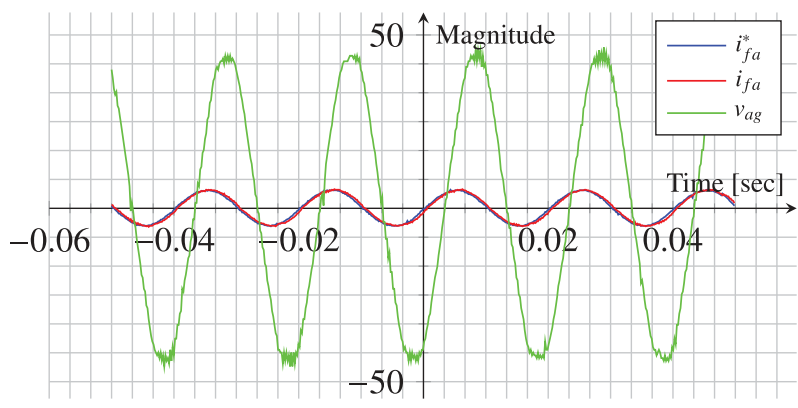

(b) Current $i_{f}$ and voltage $v_{a g}$ waveforms for half load.

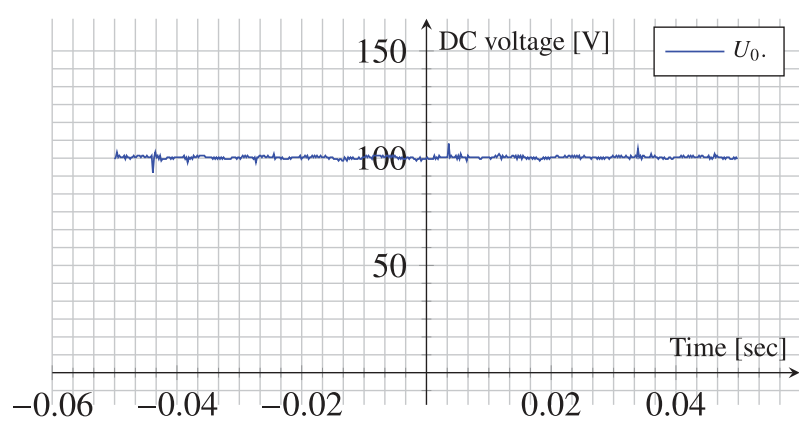

(d) DC voltage $U_{0}$.

Fig. 20. Grid-side converter for leading current for several load conditions $\left(i_{d}=-4 A\right)$.

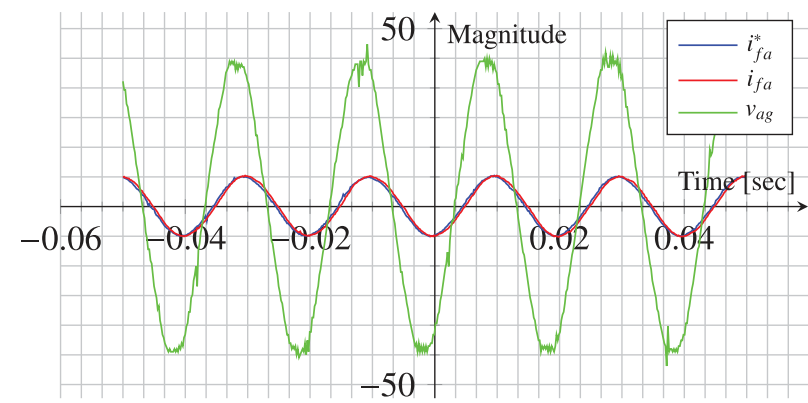

(a) Current $i_{f}$ and voltage $v_{a g}$ waveforms for full load.

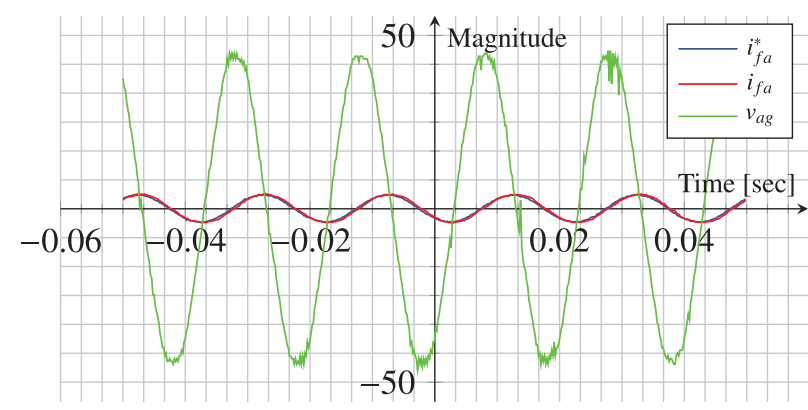

(c) Current $i_{f}$ and voltage $v_{a g}$ waveforms for no load.

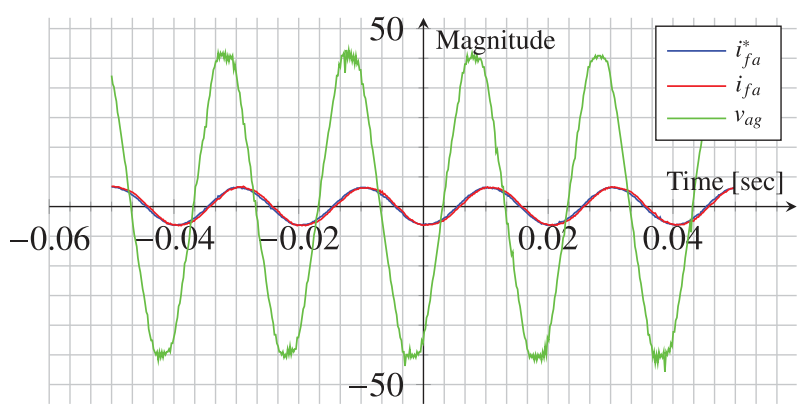

(b) Current $i_{f}$ and voltage $v_{a g}$ waveforms for half load.

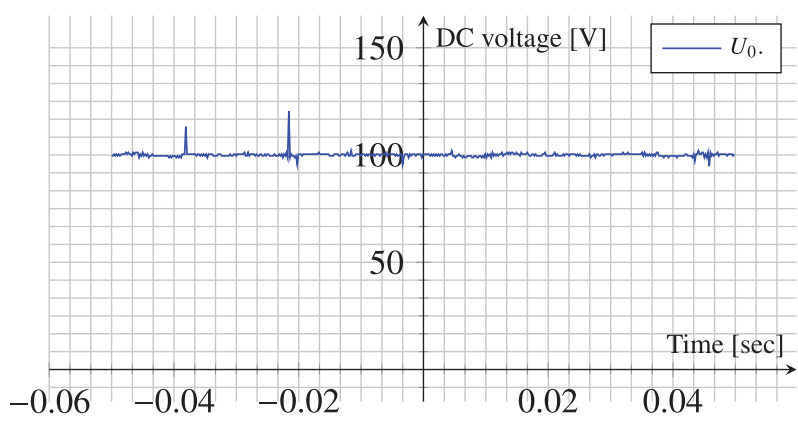

(d) DC voltage $U_{0}$.

Fig. 21. Grid-side converter for lagging current for several load conditions $\left(i_{d}=4 \mathrm{~A}\right)$. 


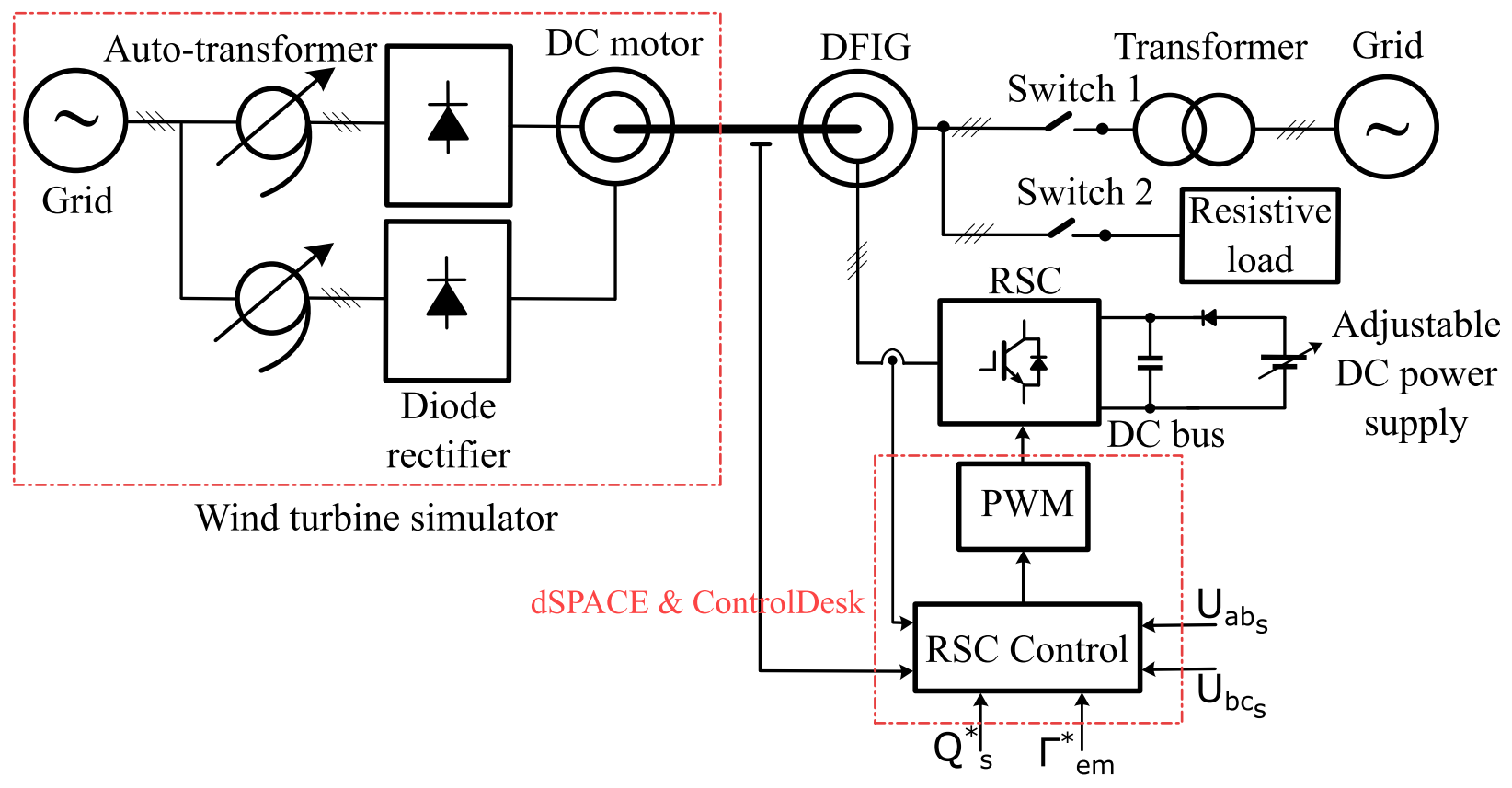

Fig. 22. Rotor-side converter control.

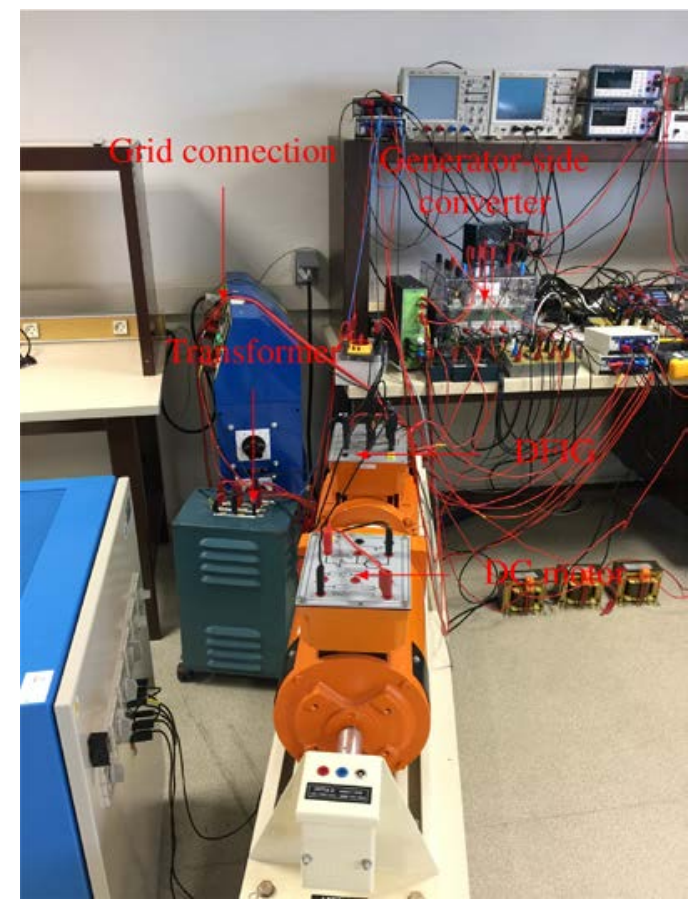

Fig. 23. DFIG and generator-side converter.

\subsection{Generator-side converter results}

The validation of the generator-side converter control has been performed based on the scheme given by Fig. 22 . For this experiment, adjustable DC power supply has been used rather than the grid-side converter. A diode is used is series in order to protect the DC supply as this structure is irreversible. The DFIG should be operated only on sub-synchronous mode, i.e. $\Omega_{M} \leq \Omega_{s}$, with $\Omega_{s}=1500 \mathrm{rpm}$ is the synchronous speed. The control algorithm is implemented using dSPACE hardware/software. A picture of the experimental setup for generator-side converter control validation is given by Fig. 23 . 


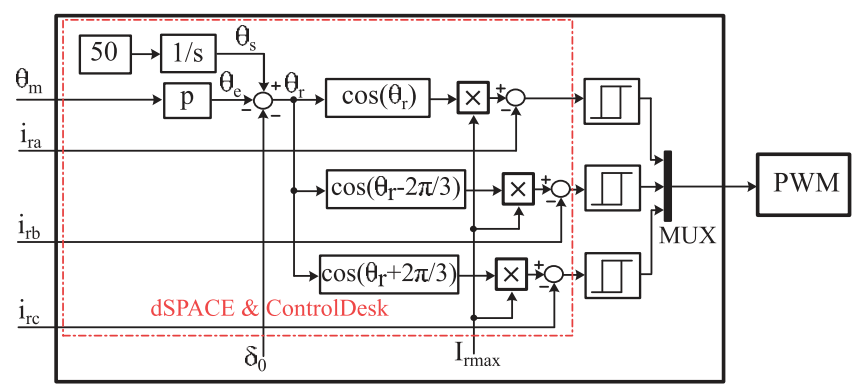

Fig. 24. Rotor-side converter: Test on resistive load.

A Fluke power quality analyser is used to visualize the active and reactive powers flow on the DFIG stator. These two quantities are controlled thanks to the rotor-side converter. Note that the active power is linked to the electromagnetic torque $\Gamma_{e m}$ developed by DFIG.

In the following, a step-by-step methodology is described in order to implement a doubly-fed induction machine in generator mode for sub-synchronous operation. Super-synchronous mode operation can not be implemented since the adjustable DC power supply is irreversible, but it is investigated for the case where the DC supply is replaced by the grid-side converter in the following sections.

\subsubsection{DFIG with stator connected to resistive load}

A first experiment has been conducted based on the scheme presented by Fig. 22 for which switch 1 is opened while switch 2 is closed. In this case, the DFIG stator is connected to the resistive load. The implemented control scheme is given by Fig. 24 and is based on rotor-currents hysteresis control. For this control a stator-generated electromotive forces (EMF) frequency is fixed to be $50 \mathrm{~Hz}$. In order to generate the rotor currents references, the rotor position is measured using incremental encoder $\theta_{m}=\frac{\theta_{e}}{p}$. These references are generated based on equations shown by Fig. 24. The three-phase rotor currents are measured using Hall effects sensors and controlled in order to follow up the required currents waveforms using hysteresis control. The output of the hysteresis control is the PWM signals to be applied to the rotor-side converter switches. For this experiment, the DFIG is driven by the DC motor and the DC voltage was adjusted to $U_{0}=70 \mathrm{~V}$. The three-phase resistive load connected to the stator is a $2 \mathrm{~kW}$ resistance with a maximum DC voltage of $U_{R L_{\max }}=220 \mathrm{~V}$. For the following experiments, the load was fixed equal to $50 \%$ of the full load. It worth to note that the load does not have any effect on the generated EMFs.

Two tuning parameters can be noticed from Fig. 24, which are the rotor current maximal reference value $I_{r m a x}$ and the angle $\delta_{0}$. Several experiments have been achieved in order to highlight the effect of these parameters. Figs. 25 and 26 give the experimental results for $I_{r \max }=1 \mathrm{~A}$ and $I_{r \max }=4 \mathrm{~A}\left(\delta_{0}=0\right)$, respectively. It can be concluded from these figures that the amplitude of the rotor currents has an impact over the amplitude of the stator EMFs. Consequently, the rotor currents reference must be increased in order to increase the generated EMFs amplitude on the stator and vice-versa.

In order to investigate the impact of the second parameter $\delta_{0}$, Fig. 27 depicts the experimental results for two different values of $\delta_{0}$, namely $\delta_{0}=0^{\circ}$ and $\delta_{0}=60^{\circ}$. These results show that the parameter $\delta_{0}$ has an impact on the phase-shift of the EMFs. This parameter is mandatory for grid connection to ensure that the stator EMFs are in-phase with the corresponding grid voltages. Two main conclusions can be drawn from this first experiments:

- Parameter $I_{\text {rmax }}$, which is the fixed rotor currents amplitude, allows adjusting DFIG stator EMF amplitude,

- Parameter $\delta_{0}$, which is the shift angle of the rotor currents, allows controlling the EMF phase-shift.

\subsubsection{DFIG with grid-connection}

In order to connect the DFIG stator to the grid, the rotor-side converter control scheme depicted by Fig. 28 has been implemented. For this second experiment, the scheme presented by Fig. 22 is investigated for which switch 1 is closed and switch 2 is opened. This way, the DFIG stator is connected to the grid through a transformer. In order to achieve gridconnection, the following successive steps must be performed:

1. The resistive load is connected to the DFIG stator and switch 1 is opened.

2. The control represented by Fig. 28 scheme is implemented and is running on dSPACE board,

- Measure $U_{a b_{s}}$ and $U_{b c_{s}}$ grid voltages for $\theta_{s}$ estimation,

- Measure $\theta_{m}$ and compute $\theta_{r}$,

- Compute the rotor reference currents based on equations given by Fig. 28.

- Currents control regulator is hysteresis controllers, which outputs PWM signals controlling the converter switches.

- Measure and visualize two grid voltages, for instance $V_{a s}$ and $V_{b s}$ and the corresponding stator EMFs for instance $E_{a s}$ and $E_{b s}$,

- Increase the rotor currents maximum value to ensure that the grid voltages and the EMFs have the same amplitude, 


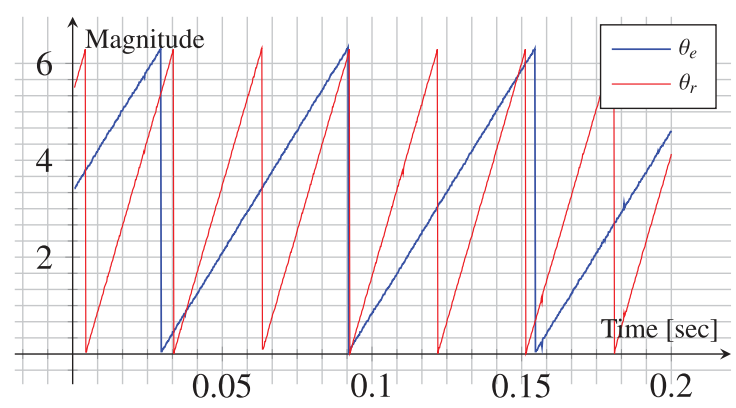

(a) Rotor electrical position and rotor currents angle.

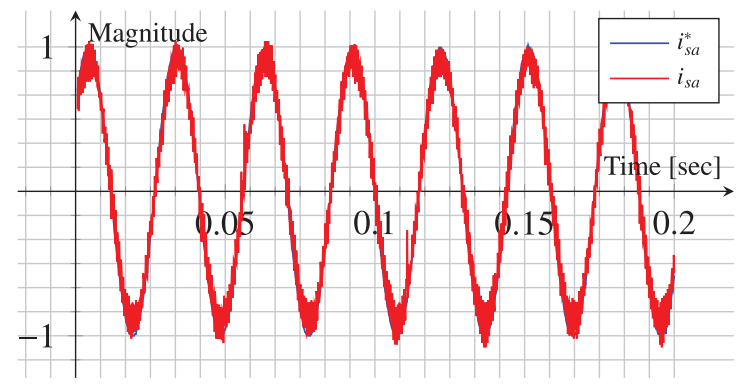

(b) Stator current $i_{s a}$.

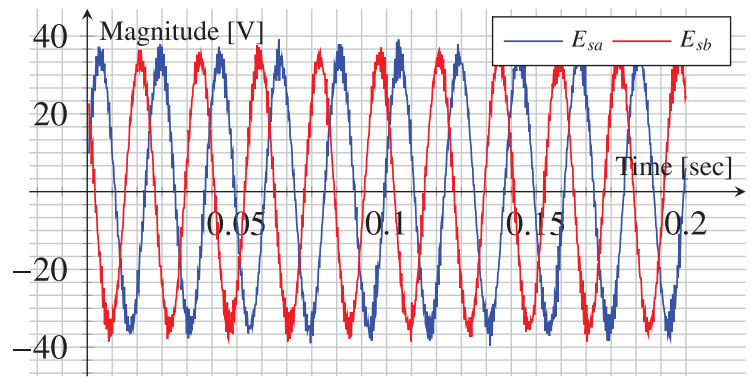

(c) Stator electromotive forces.

Fig. 25. Rotor-side converter scalar torque control for $I_{\text {rmax }}=1 \mathrm{~A}$ and $\delta_{0}=0$.

- Tune $\delta_{0}$ in order to get $V_{a s}$ in-phase with $E_{a s}$ and $V_{b s}$ in-phase with $E_{b s}$,

- Turn-on switch 1 and then turn-off switch 2. The DFIG is connected to the grid,

- Control the active and reactive powers flow through parameter $\delta$ and $I_{\text {rmax }}$.

The experimental results for grid-connection are depicted by Fig. 29. This figure shows the stator electrical angle estimated based on the PLL and the rotor electrical angle measured based on the incremental encoder. These parameters are used to generate the rotor currents references. The rotor phase current $i_{r a}$ and its reference $i_{r a}^{*}$ are depicted by Fig.. Rotor currents have been controlled based on hysteresis controllers. A dSPACE \& ControlDesk application has been developed to allow varying $I_{r \max }$ and $\delta_{0}$ in real-time. This is done in order to control the amplitude and the phase of the generated stator EMFs as discussed in the previous section. Fig. 29 shows the grid voltages $V_{s a}, V_{s b}$ and the corresponding EMFs $E_{s a}, E_{s b}$ in the case of perfect match. In this case, the two control parameters are equal to $I_{r \max }=5 \mathrm{~A}$ and $\delta_{0}=90^{\circ}$. While the voltages match, switch 1 is turned-on, then switch 2 is turned-off. Therefore, DFIG stator windings are connected to the grid. In this situation $V_{s a}=E_{s a}$ and $V_{s b}=E_{s b}$, thus there is no active and no reactive powers flowing between DFIG stator and the main grid.

To control the active and reactive powers flow between DFIG stator and the grid, the two parameters $I_{r m a x}$ and $\delta$ should be adjusted. A Fluke power flow analyser has been used to visualize the power exchange between DFIG and the grid. Figs. 30 and 31 give the Fresnel diagram for capacitance and inductor behaviors.To summarize the previously presented aspects regarding power flow:

- For $I_{\text {max }}=5 \mathrm{~A}$ and $\delta=0$, there is no power exchange between grid and DFIG.

- $\delta=0$ and varying $I_{r \max }$ allows controlling the reactive power flow between the grid and the DFIG-stator. 


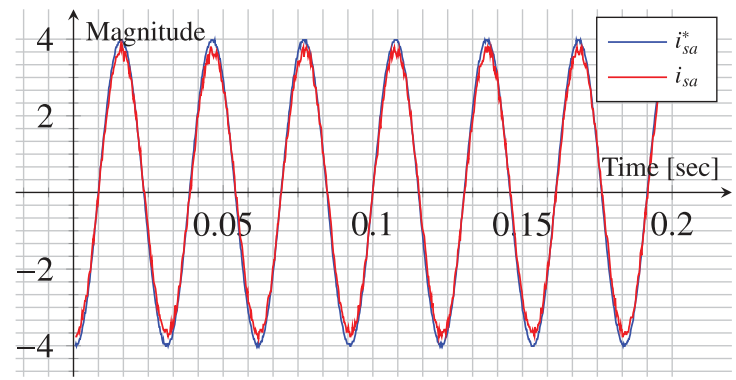

(a) Stator current $i_{s a}$.

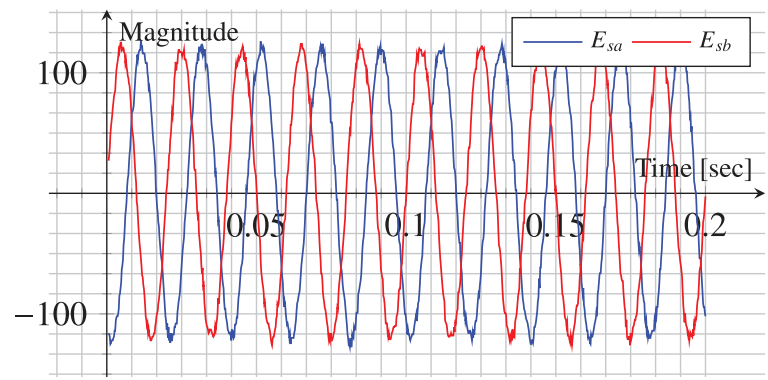

(b) Stator electromotive forces.

Fig. 26. Rotor-side converter scalar torque control for $I_{r \max }=4 \mathrm{~A}$ and $\delta_{0}=0$.

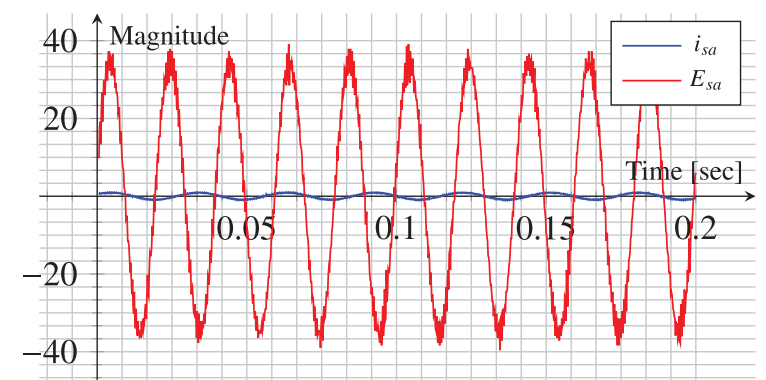

(a) Stator redcurrent $i_{s a} \operatorname{emf} E_{s a}$ for $\delta_{0}=0^{\circ}$.

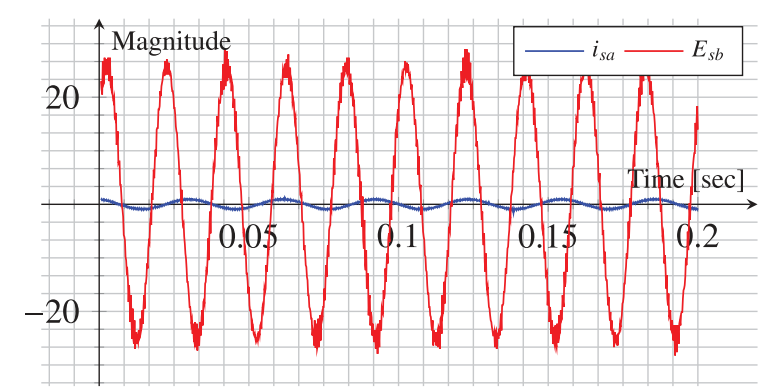

(b) Stator current $i_{s a}$ emf $E_{s a}$ for $\delta_{0}=60^{\circ}$.

Fig. 27. Rotor-side converter scalar torque control for varying $\delta_{0}\left(I_{r \max }=1 \mathrm{~A}\right)$.

- Varying both $\delta$ and $I_{r \max }$ allows controlling both active and reactive power. For $\delta=90^{\circ}$ and $\delta=-90^{\circ}$, the reactive power flow is zero and the transfer of the active power is maximal (unity power factor).

\subsection{DFIG and back-to-back converter results}

The experimental setup given by Fig. 12 has been implemented in order to prove the effectiveness of the overall control scheme to emulate a DFIG-based WEC system. This scheme has been modified by introducing two resistances, one in 


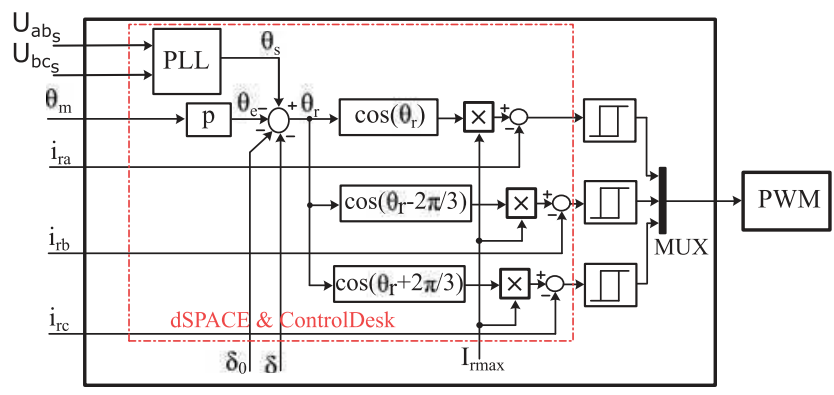

Fig. 28. Rotor-side converter: Grid-connection.

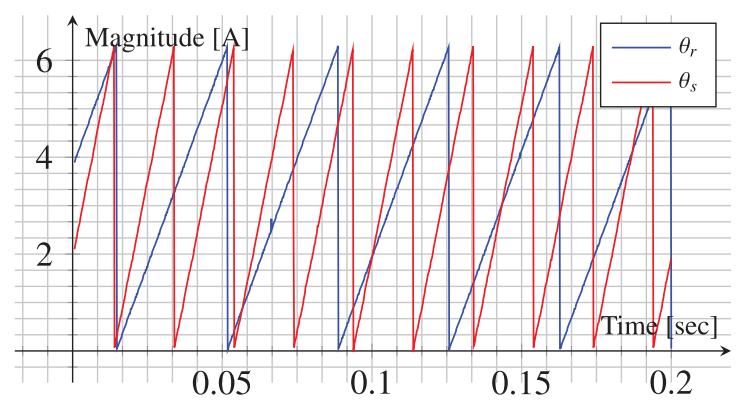

(a) Rotor electrical angle $\theta_{r}$ and stator electrical angle $\theta_{s}$.

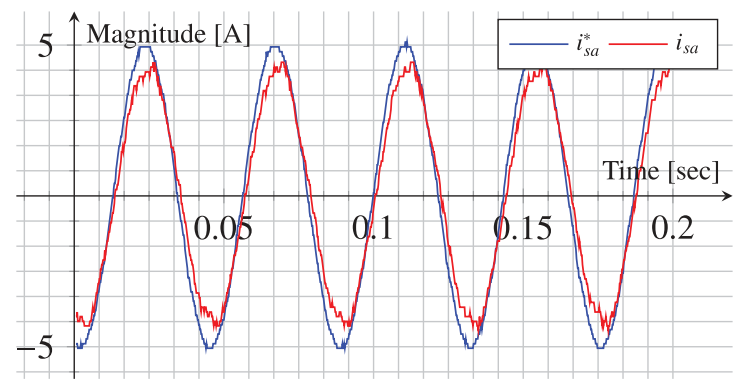

(b) Stator current $i_{s a}$

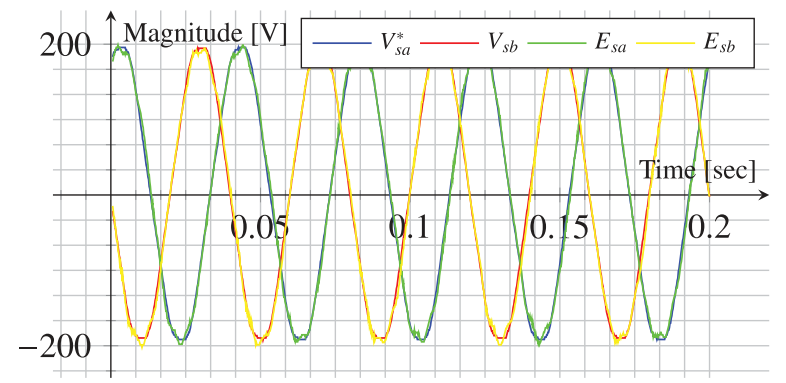

(c) Grid Voltages and EMFs.

Fig. 29. Rotor-side converter scalar torque control and grid-connection.

parallel with the DC bus capacitor and the other in series between DC bus capacitor and the generator-side converter for safe connection between the two converters. These resistances should be variable ones since they must be cancelled during converters commissioning. The methodology used for the implementation of the overall DFIG-based WEC system with connection to the grid is given as follows:

- Grid-side converter commissioning. The DC bus is controlled to maintain DC voltage equal to $100 \mathrm{~V}$. The line currents are in-phase with grid voltages. 


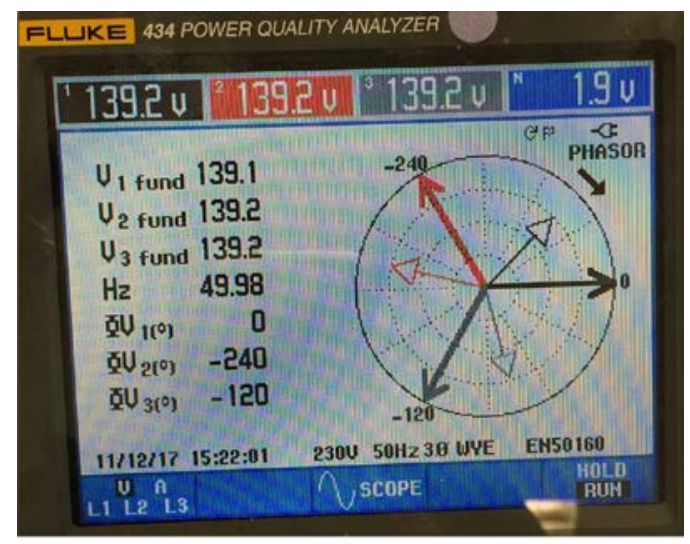

(a) Reactive power flow from DFIG to grid.

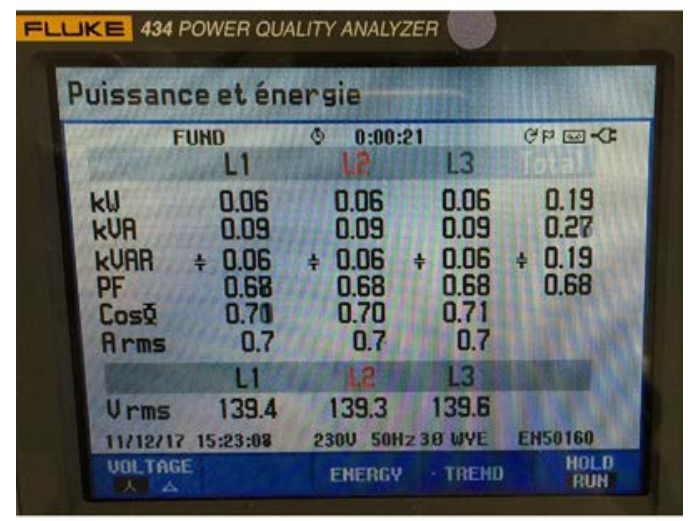

(b) Reactive power flow from grid to DFIG.

Fig. 30. DFIG and generator-side converter: Power flow control (capacitor).

- The rotor currents are controlled to be sinusoidal. The parallel and series resistances are cancelled gradually while supervizing line and rotor currents.

- DC motor, which is emulating wind turbine, drives the DFIG. DC motor produces continuous rotation.

- Rotor currents are controlled based on ControlDesk in order to ensure induced EMFs to have the same amplitude as grid voltages. Phase currents are also controlled is order to ensure that grid phase 1 is in-phase with stator first winding and grid phase 2 in phase with the second winding.

- Ones grid voltages and induced stator EMFs are superimposed, switch between the grid and stator windings is closed. In this situation, the angle $\delta$ between EMFs and grid voltages is zero. There is no reactive and no active powers flowing between the grid and DFIG stator.

DFIG-stator power transfer is controlled as follows:

- Maintaining $\delta=0$ and controlling the amplitude of the rotor currents allows controlling the reactive power flow between the DFIG stator and the grid (reactive power compensation).

- Controlling the angle $\delta$ between the EMFs and grid voltages allows controlling the active power flow on the stator. For $\delta=90^{\circ}$ and $\delta=-90^{\circ}$, the reactive power flow is zero and the transfer of the active power is maximal (unity power factor).

Fig. 32 depicts the power transfer in the rotor side. It can be seen from this figure that DFIG rotor power transfer depends on the rotational speed of DC motor as follows:

- In sub-synchronism mode: the DC motor rotational speed is less than synchronous speed and the active power flow is from the grid to the DFIG rotor. The line current is in-phase with grid voltage as shown by Fig. 33a.

- In super-synchronism mode: the DC motor rotational speed is greater than synchronous speed and the active power flow is from the DFIG rotor to the grid. The line current and the grid voltage are in phase-opposition as shown by Fig. 33. 


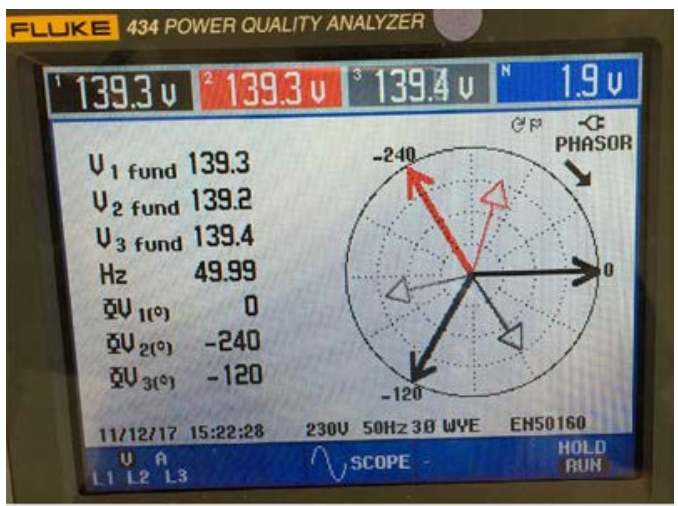

(a) Reactive power flow from DFIG to grid.

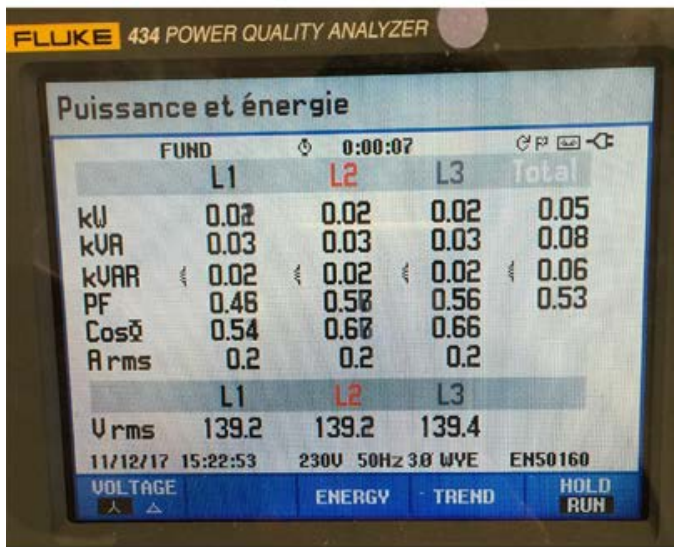

(b) Reactive power flow from grid to DFIG.

Fig. 31. DFIG and generator-side converter: Power flow control (inductor).

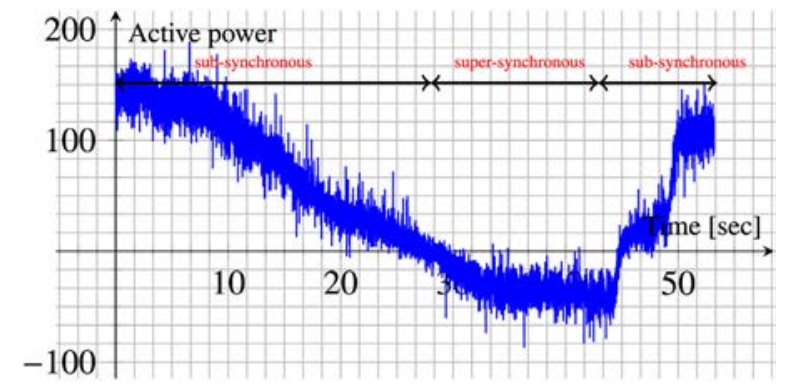

(a) Active power in DFIG rotor.

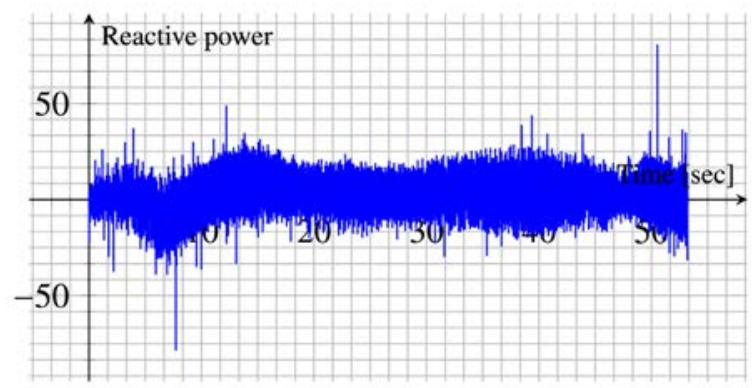

(b) Reactive power in DFIG rotor.

Fig. 32. Rotor-side converter for sub-synchronous and super-synchronous modes. 


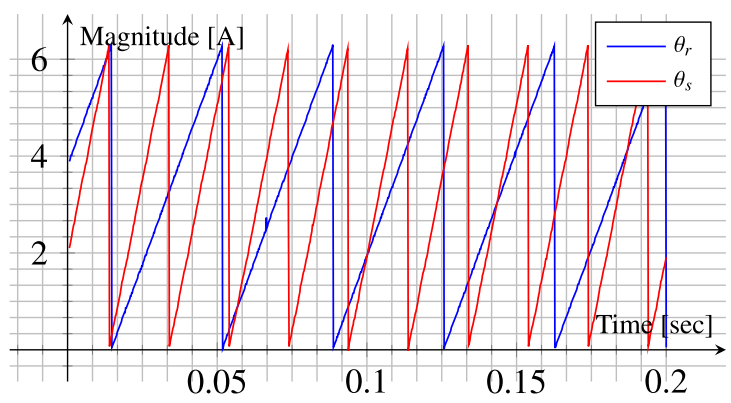

(a) Rotor electrical angle $\theta_{r}$ and stator electrical angle $\theta_{s}$.

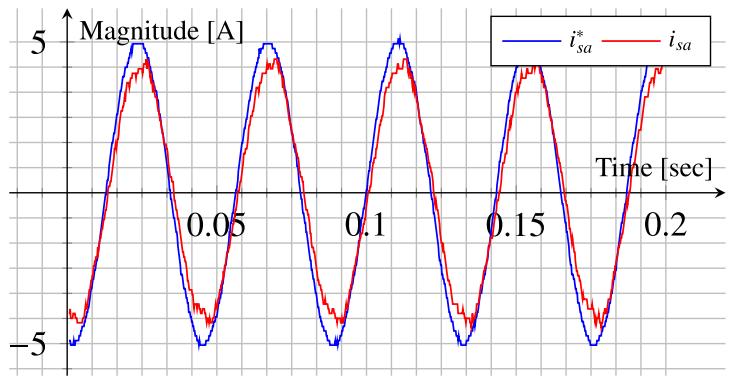

(b) Stator current $i_{s a}$.

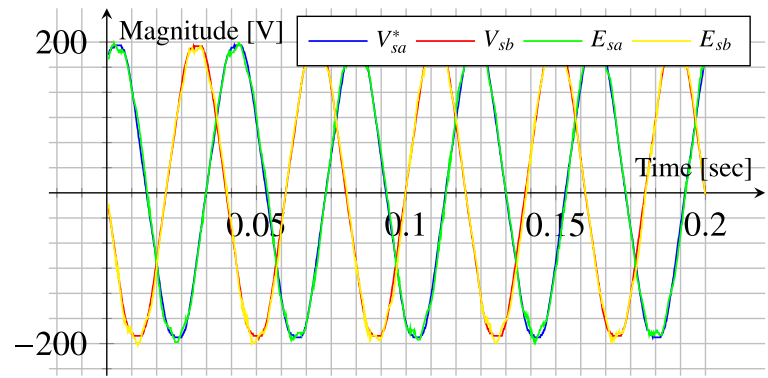

(c) Grid Voltages and EMFs.

Fig. 33. Rotor-side converter for sub-synchronous and super-synchronous modes.

\section{Discussion}

In this paper a step-by-step modeling and digital control design methodology for a simulation and experimental wind energy conversion platform has been described. The realized test-rig enables emulating the behavior of DFIG-based WEC and implementing a digital control of wind energy production systems. The experimental platform allows accurate dynamic reproduction under deterministic and realistic conditions of wind energy conversion systems. The paper is intended for master degree students, PhD students, or even young engineers in the field of WEC systems. It presents a methodology for designing, sizing, and emulating in a thorough and coherent way a wind turbine for specific power and rated wind speed on laboratory test bench. Moreover, it is of great interest for understanding controllers parameters derivation, active and reactive powers control laws computation, grid-integration, and energy management of DFIG-based WEC.

The presented study allows demonstrating the possibilities offered by a DFIG-based WEC for voltage and frequency regulation. In fact, controlling the reactive power allows participating in voltage regulation, while controlling active power allows participating in frequency regulation through the overall power grid. Moreover, currents injected into the grid are controlled to be sinusoidal enhancing THD and therefore improving wind turbine power quality.

The detailed simulation versus experiments study has two main objectives:

- It provides a turnkey solution for the development of simulation and experimental platforms for education purposes.

- The proposed platform can also be used for research purposes. In particular, it allows validating advanced control strategies for DFIG-based WEC [2], but not only. Indeed, it has already been used for faults diagnosis in [23].

Even if the proposed step-by-step methodology has been developed for DFIG-based WEC, it is exactly the same for PMSG-based WEC. In fact, for PMSG-based WEC power converters are connected to the stator. The back-to-back converter is 
in this case designed for the wind turbine nominal power. The grid-side converter control strategy is exactly the same as for DFIG-based WEC. However, the generator-side converter is used for PMSG control in order to implement MPPT for partial loading and to limit the extracted power for full loading. Furthermore, the developed platform could also be used for the study of tidal and wave energy converters as they typically use the same drivetrain as wind turbines [24]. This has already been done in an emulation-based study of a small power tidal turbine [25].

Exponential increase in global energy demand, rapid depletion of fossil fuels, and environmental issues have lead to large penetration of renewable energy resources, among which wind energy is a promising resource. Voltage and frequency regulation is mandatory to meet grid codes. In fact, with the increase of wind farms capacity, some regulations for gridconnection are imposed. Specifically, wind farms are required to provide some sort of local (voltage regulation) or even global ancillary (frequency regulation) services. Among these services, wind farms are asked to enhance energy quality by THD management. Moreover, voltage/reactive power and frequency/active power controls are mandatory to ensure the power grid stability. Finally, modern large-scale wind turbines are now required to include systems that allow them ridingthrough power grid voltage dips or frequency deviations.

\section{Conclusion and future works}

This paper has dealt with key issues related to doubly-fed induction generators-based wind turbines, including system architecture, modeling and control objectives, and active/reactive powers transfer to the power grid. Power electronic converters and conventional transformers have been proven to be efficient to carry out tasks needed to interface this type of wind turbines to the power grid. The proposed digital control strategy has been successfully implemented on dSPACE board using Embedded Coder from Matlab/Simulink. Specifically, the control strategy has been implemented and experimentally validated for each subsystem, namely: grid-side converter, rotor-side converter, and grid-connection. In this context, a labscale experimental platform has been designed and realized. The conducted experiments have highlighted the control of the active and reactive powers through both the rotor and the stator of DFIG as well as the control of currents waveforms in order to enhance THD.

Future works should be investigating the implementation of permanent magnet synchronous generators-based wind energy conversion, then highlighting the clear ability of the developed platform to emulate both wind and tidal turbines whatever the used generator topology.

\section{Appendix A. Park/Clarke Transform}

Recall that Park transform is a combination of Concordia transform $\mathbf{C}_{x y}$ and rotation matrix $\mathbf{R}(\theta)$. Park transform allows to transform three-phase variables to quadratic two-phase variables associated with homopolar component (zero in our case since the neutral point is not connected).

\section{A.1. Concordia transform $\boldsymbol{C}_{\mathrm{xy}}$}

Concordia transform allows decorrelating coupling inductive matrix between phases. However, it does not eliminate the dependence of mutual inductances on electrical angle $\theta_{e}$. It allows to get two rotating axes, generally called $\alpha$ - and $\beta$-axis.

$$
\left\{\begin{array}{l}
\mathbf{x}_{a b c}=\mathbf{C}_{32} \mathbf{x}_{\alpha \beta} \\
\mathbf{x}_{\alpha \beta}=\mathbf{C}_{23} \mathbf{x}_{a b c}
\end{array}\right.
$$

where, $\mathbf{C}_{32}$ is inverse Concordia transform and $\mathbf{C}_{23}=\mathbf{C}_{32}^{T}$ is direct Concordia transform, with (.) $)^{T}$ corresponds to matrix transpose. $\mathbf{C}_{32}$ is given by

$$
\mathbf{C}_{32}=k\left[\begin{array}{cc}
1 & 0 \\
\frac{-1}{2} & \frac{\sqrt{3}}{2} \\
\frac{-1}{2} & \frac{-\sqrt{3}}{2}
\end{array}\right]
$$

where $k=\frac{2}{3}$ for amplitude-invariant Park transform and $k=\sqrt{\frac{2}{3}}$ for power-invariant Park transform. In this paper, the adopted one is the amplitude-invariant Park transform.

\section{A.2. Rotation matrix $\boldsymbol{R}(\theta)$}

Rotation matrix $\mathbf{R}(\theta)$ allows to eliminate the dependence of remaining variables on electrical angle $\theta_{e}$, that is given by:

$$
\mathbf{R}(\theta)=\left[\begin{array}{cc}
\cos (\theta) & -\sin (\theta) \\
\sin (\theta) & \cos (\theta)
\end{array}\right]
$$


It allows to transform the stationary $\alpha \beta$-reference frame to $d q$-synchronous (rotating) Park reference frame as follows:

$$
\left\{\begin{array}{l}
\mathbf{x}_{\alpha \beta}=\mathbf{R}(\theta) \mathbf{x}_{d q} \\
\mathbf{d} \mathbf{q}_{d q}=\mathbf{R}(-\theta) \mathbf{x}_{\alpha \beta}
\end{array}\right.
$$

\section{Appendix B. Test rig parameters}

\section{B.1. Wind}

\section{Table B.1}

Wind parameters.

\begin{tabular}{lll}
\hline Symbol & Quantity & Value \\
\hline$v_{w_{\text {in }}}$ & Cut-in wind speed & $5-\mathrm{m} / \mathrm{s}$ \\
$v_{w_{\text {rated }}}$ & Rated wind speed & $13-\mathrm{m} / \mathrm{s}$ \\
$v_{w_{\text {out }}}$ & Cut-out wind speed & $25-\mathrm{m} / \mathrm{s}$ \\
$\rho$ & Air density & $1.225-\mathrm{kg} / \mathrm{m}^{3}$ \\
\hline
\end{tabular}

B.2. Turbine and gearbox

Table B.2

Turbine and gearbox parameters.

\begin{tabular}{lll}
\hline Symbol & Quantity & Value \\
\hline$R_{T}$ & Turbine radius & $1.089-\mathrm{m}$ \\
$G_{r}$ & Gearbox ratio & $2.4412 \approx \frac{61}{25}$ \\
$C_{p_{\max }}$ & Maximal power coefficient & 3.5 \\
$\lambda_{\text {opt }}$ & Optimal tip-speed ratio & 7 \\
\hline
\end{tabular}

B.3. Doubly-fed induction generator parameters

Table B.3

Rated data of doubly-fed induction generator.

\begin{tabular}{lll}
\hline Symbol & Quantity & Machine \\
\hline$P_{n}$ & Nominal power & $1.5-\mathrm{kW}$ \\
$\Omega_{n}$ & Nominal speed & $1420-\mathrm{rpm}$ \\
$J_{t}$ & Inertia & $0.0426-\mathrm{kg} \cdot \mathrm{m}^{2}$ \\
$f_{v}$ & Viscous friction coefficient & $0.002-\mathrm{N} . \mathrm{m} . \mathrm{s} / \mathrm{rad}$ \\
$\Gamma_{s}$ & Dry friction torque & $0.8399-\mathrm{N} . \mathrm{m}$ \\
$p$ & Number of pole pairs & 2 \\
$f_{s}$ & Supply frequency & $50-\mathrm{Hz}$ \\
$V_{s n}$ & Stator supply voltage & $230 / 400-\mathrm{V}$ \\
$I_{s n}$ & Stator nominal current & $7.5 / 4.4-\mathrm{A}$ \\
$V_{r n}$ & Rotor supply voltage & $140-\mathrm{V}$ \\
$I_{r n}$ & Rotor nominal current & $6.5-\mathrm{A}$ \\
$N_{s}$ & Number of stator slots & 48 \\
$R_{s}$ & Stator phase resistance & $1.75-\Omega$ \\
$R_{r}$ & Rotor phase resistance & $1.68-\Omega$ \\
$L_{s}$ & Stator phase inductance & $295-\mathrm{mH}$ \\
$L_{r}$ & Rotor phase inductance & $104-\mathrm{mH}$ \\
$M_{0}$ & Mutual inductance & $165-\mathrm{mH}$
\end{tabular}




\section{Table B.4}

Power converters, DC bus and transformer parameters.

\begin{tabular}{lll}
\hline Symbol & Quantity & Value \\
\hline$C$ & DC bus capacitor & $1000-\mu \mathrm{F}$ \\
$U_{0_{\max }}$ & DC bus maximal voltage & $500-\mathrm{V}$ \\
$U_{0}$ & DC bus reference voltage & $100-\mathrm{V}$ \\
$R$ & GSC-to-grid filter resistance & $1-\Omega$ \\
$L$ & GSC-to-grid filter inductance & $5-\mathrm{mH}$ \\
$V_{g}$ & Grid phase-to-neutral voltage (transformer secondary windings voltage) & $230-\mathrm{V}$ \\
$V_{p}$ & Transformer primary windings voltage & $30-\mathrm{V}$ \\
\hline
\end{tabular}

\section{References}

[1] Wu B, Lang Y, Zargari N, Kouro S. Power conversion and control of wind energy systems, 76. John Wiley \& Sons; 2011.

[2] Benbouzid M, Beltran B, Amirat Y, Yao G, Han J, Mangel H. Second-order sliding mode control for dfig-based wind turbines fault ride-through capability enhancement. ISA transactions May 2014;53(3):827-33.

[3] Hansen AD, Altin M, Iov F. Provision of enhanced ancillary services from wind power plants-examples and challenges. Renewable Energy November 2016:97:8-18.

[4] Boutoubat M, Mokrani L, Machmoum M. Control of a wind energy conversion system equipped by a DFIG for active power generation and power quality improvement. Renewable Energy February 2013;50:378-86.

[5] Bevrani H, Ghosh A, Ledwich G. Renewable energy sources and frequency regulation: survey and new perspectives. IET Renewable Power Generation September 2010;4(5):438-57.

[6] Amuthan N, Subburaj P, Mary PM. Voltage sag ride through using improved adaptive internal model controller for doubly fed induction generator wind farms. Computers \& Electrical Engineering 2013;39(2):214-24.

[7] Salem SMS. Study of wind turbine based self-excited induction generator under non-linear resistive loads as a step to solve the Egypt electricity crisis. Computers \& Electrical Engineering 2016;51:1-11.

[8] Munteanu I, Bacha S, Bratcu AI, Guiraud J, Roye D. Energy-reliability optimization of wind energy conversion systems by sliding mode control. IEEE Transactions on Energy Conversion Sept. 2008;23(3):975-85.

[9] Lhachimi H, Sayouti Y, El Kouari Y. Optimal improvement of direct power control strategy based on sliding mode controllers. Computers \& Electrical Engineering 2018;71:637-56.

[10] She X, Huang AQ, Wang F, Burgos R. Wind energy system with integrated functions of active power transfer, reactive power compensation, and voltage conversion. IEEE Transactions on Industrial Electronics Oct. 2013;60(10):4512-24.

[11] Kot R, Rolak M, Malinowski M. Comparison of maximum peak power tracking algorithms for a small wind turbine. Mathematics and Computers in Simulation May 2013:91:29-40.

[12] Blaabjerg F, Ma K. Wind energy systems. Proceedings of the IEEE Nov. 2017;105(11):2116-31.

[13] Ghennam T, Aliouane K, Akel F, Francois B, Berkouk E. Advanced control system of DFIG based wind generators for reactive power production and integration in a wind farm dispatching. Energy Conversion and Management November 2015;105:240-50

[14] Kanjiya P, Ambati BB, Khadkikar V. A novel fault-tolerant DFIG-based wind energy conversion system for seamless operation during grid faults. IEEE Transactions on Power Systems May 2014;29(3):1296-305.

[15] Kumar D, Chatterjee K. A review of conventional and advanced mppt algorithms for wind energy systems. Renewable and sustainable energy reviews March 2016;55:957-70.

[16] Mohanty A, Viswavandya M, Ray PK, Patra S. Stability analysis and reactive power compensation issue in a microgrid with a DFIG based WECS International Journal of Electrical Power \& Energy Systems November 2014;62:753-62.

[17] Geng H, Liu C, Yang G. LVRT capability of DFIG-based WECS under asymmetrical grid fault condition. IEEE transactions on Industrial Electronics June 2013;60(6):2495-509.

[18] Justo JJ, Mwasilu F, Jung J-W. Doubly-fed induction generator based wind turbines: A comprehensive review of fault ride-through strategies. Renewable and sustainable energy reviews May 2015;45:447-67.

[19] Kairous D, Wamkeue R. DFIG-based fuzzy sliding-mode control of WECS with a flywheel energy storage. Electric Power Systems Research December 2012;93:16-23.

[20] Zia MF, Elbouchikhi E, Benbouzid M. Microgrids energy management systems: A critical review on methods, solutions, and prospects. Applied energy July 2018;222:1033-55.

[21] Zia MF, Elbouchikhi E, Benbouzid M. Optimal operational planning of scalable dc microgrid with demand response, islanding, and battery degradation cost considerations. Applied energy March 2019;237:695-707.

[22] Jalili K, Bernet S. Design of lcl filters of active-front-end two-level voltage-source converters. IEEE Transactions on Industrial Electronics May 2009;56(5):1674-89.

[23] Elbouchikhi E, Amirat Y, Feld G, Benbouzid M. Generalized likelihood ratio test-based approach for stator faults detection in a PWM inverter-fed induction motor drive. IEEE Transactions on Industrial Electronics Aug. 2019;66(8):6343-53.

[24] Benelghali S, Benbouzid MEH, Charpentier JF, Ahmed-Ali T, Munteanu I. Experimental validation of a marine current turbine simulator: Application to a PMSG-based system second-order sliding mode control. IEEE Trans Industrial Electronics January 2011;58(1):118-26.

[25] Amirat Y, Feld G, Elbouchikhi E, Benbouzid M, Kermarrec H, Ruiz N, et al. Design and applications of a tidal turbine emulator based on a pmsg for remote load. In: Proceedings of the 2017 IEEE IECON. IEEE; November 2017. p. 2437-41. 